\title{
Pathology of hearts after aortocoronary saphenous vein bypass grafting for coronary artery disease, studied by post-mortem coronary angiography
}

\author{
Brian E. Heard \\ From the Cardiothoracic Institute, Brompton Hospital, London, and London Chest Hospital
}

A detailed pathological study was made in 10 patients dying up to 13 months after aortocoronary saphenous vein bypass grafting for coronary atherosclerosis. The coronary arteries and vein grafts were investigated by injection with a radio-opaque mass, radiography, dissection, and histology.

The report is to some extent historical since the patients died during a period when the operation was first being introduced into two cardiothoracic hospitals. About 80 operations were performed during the time the 10 deaths occurred, a mortality of 12.5 per cent (including cases followed up to 13 months after operation). Seven of the patients were operated on for intractable angina and 3 with a view to aneurysmectomy. All the patients selected for operation were severely disabled despite medical treatment.

The main cause of death was extremely severe coronary artery disease and its effects on the left ventricle; in one case, over two-thirds of the left ventricle had been destroyed by infarction before operation. Other causes or contributing causes of death were pulmonary embolism, myocardial infarction complicating angiography (ostial stenosis), and cerebral damage.

Ten of the 14 vein grafts (71\%) were patent at necropsy. A free flow of injection medium usually occurred between patent grafts and coronary arteries. Thrombosis of a graft was thought to have contributed to death in 3 patients, but not in a fourth who died of pulmonary embolism. Since thrombosis of grafts was usually secondary to poor run-off of blood into severely atheromatous coronary arteries, this was also an indirect effect of the advanced coronary arterial disease. In one case, thrombosis followed severe chronic intimal thickening of a graft in place for 13 months.

The study of these deaths emphasizes that in some patients the pathological changes in the coronary arteries and left ventricle are too severe for them to benefit from surgery. Vein grafts cannot be expected to distribute blood effectively through grossly narrowed coronary arteries. In addition, when a large part of the left ventricle is infarcted or scarred, it is almost certain that improving the blood supply by grafting will not result in significant regeneration of cardiac muscle.

Since the time when this study was made, there have been few deaths among the many vein graft operations subsequently carried out in the hospitals involved. The two most important factors thought responsible for the improvement are the selection of cases more suitable for surgery by continued improvement of diagnostic techniques, and also the employment of more radical surgical procedures in the form of coronary endarterectomy and the insertion of more grafts per patient.

A major advance in the treatment of ischaemic heart disease has been the introduction of aortocoronary bypass surgery, using autologous saphenous vein grafts (Favaloro, 1968, 1970, 1972; Favaloro et al., 1970; Johnson et al., 1969, 1970b; Johnson, Auer, and Tector, 1970a; Grondin et al., Received 22 October 1975. 1971a, b, c, d, e; Alderman et al., 1973). The operation is performed mainly for very severe angina pectoris resistant to medical treatment. The hospital mortality is low, and patients are commonly freed of their angina and able to return to work (Gott, 1974; Anderson et al., 1972; Cooley et al., 1973). Sometimes an internal mammary 
artery is used instead of a vein graft, mainly for the anterior descending artery (Green, 1972). It is generally agreed that the operation should be performed only in specialized centres, where clinical facilities include investigation by coronary angiography by the method of Sones and Shirey (1962) and where the operative mortality is usually less than 5 per cent (Balcon et al., 1974).

The necropsies described here were performed during a period when the operation, which originated in the United States, was being introduced into two cardiothoracic hospitals in London. In order to determine as precisely as possible why these particular patients had not benefited from surgery, a detailed study of the hearts was made, including post-mortem coronary and vein graft angiography followed by radiography, dissection, and histological examination.

\section{Subjects and methods}

Ten patients died between 1 January 1971 and 31 December 1972. Full necropsies were performed on 8 of the patients but the heart only was examined in Cases 2 and 3. At the time of necropsy, special care was taken while opening the thorax since sometimes an anterior vein graft was found to be adherent to the back of the sternum. The heart was removed intact and preserved deep-frozen until 12 hours before the injection time, when it was thawed slowly in a refrigerator at $4^{\circ} \mathrm{C}$.

For the vascular injections, small cannulae were tied into the origins of the coronary arteries and/or into the aortic ends of the saphenous vein grafts. The injection mass was composed of 'Micropaque' (Damancy and Company, Ltd.) $330 \mathrm{ml}$, gelatin powder $33 \mathrm{~g}$, water $130 \mathrm{ml}$, and a few crystals of thymol, and was prepared well in advance. The heart and also a bottle containing the injection mass were warmed in hot tap water at 50 to $55^{\circ} \mathrm{C}$, and the mass was then injected at a pressure of 120 $\mathrm{mmHg}(16.0 \mathrm{kPa})$ (supplied by a cylinder of compressed air) for 20 minutes. The heart was then cooled in iced water, with the injection pressure maintained, and was fixed in formol saline. During the injection procedure, intercommunications between vein grafts and coronary arteries were tested by perfusing certain vessels separately and observing reflux in others. The composition of the injection mass was such that it filled only vessels down to $50 \mu$ internal diameter, which was ideal for the present purpose; injecting smaller vessels would have obscured the larger vessels by a haze in $x$-rays. Several transverse slices about $0.5 \mathrm{~cm}$ thick were cut from the lower halves of the ventricles, starting at the apex, and then the base of the heart was opened out for radiography by the 'unrolling' dissection technique of Schlesinger (1938). The tricuspid and mitral valves were removed intact for a separate study.

Radiographs of all slices and of the unrolled bases were taken with an A.E.I. Raymax 50 Superficial Therapy Unit in a lead-screened cabinet. Exposure times were between 30 and 45 minutes at $30 \mathrm{kV}$ and $3 \mathrm{~mA}$, using Kodaline standard film and Kodak D11 or D76 developer.

The condition of the grafts and coronary arteries was also determined by dissection, using the radiographs as a guide and making notes on paper tracings of them. Blocks of tissue were embedded in paraffin wax and sections were stained with haematoxylin and eosin, and with Verhoeff's elastic and van Gieson's stains. Recent infarcts were stained by the HBFP method ${ }^{1}$ (Lie et al., 1971; Nayar and Olsen, 1974).

\section{Results}

There were 10 cases, 9 men and 1 woman, and their ages ranged from 41 to 63 (mean 54.9) years.

\section{Case 1}

A man of 57 years suffered from stable angina pectoris for 5 years; during the last 6 months of his life he became almost totally incapacitated by angina which was resistant to medical treatment. Surgery was offered as the only hope of relief, and coronary cineangiography was performed as an essential step before vein grafting. During this procedure he developed ventricular fibrillation, and at an emergency operation two reversed saphenous vein grafts were inserted from the aorta into the anterior and posterior descending coronary arteries. However, part of the left ventricle was found to be newly infarcted, and he died shortly after operation from irreversible ventricular fibrillation.

At necropsy, the heart weighed $425 \mathrm{~g}$. The ostia of both left and right coronary arteries were found to be severely stenosed by atherosclerosis and cannulae could be inserted only with difficulty. There was no reverse flow of medium in the vein grafts when the coronary arteries were perfused (an occasional occurrence observed by others). However, the grafts were patent and were cannulated at the aortic end and perfused separately. Radiographs showed that the left coronary artery was dominant; the right coronary artery was short and did not reach to the posterior interventricular sulcus. The

${ }^{1}$ Haematoxylin, basic fuchsin, picric acid (Lie's stain). 


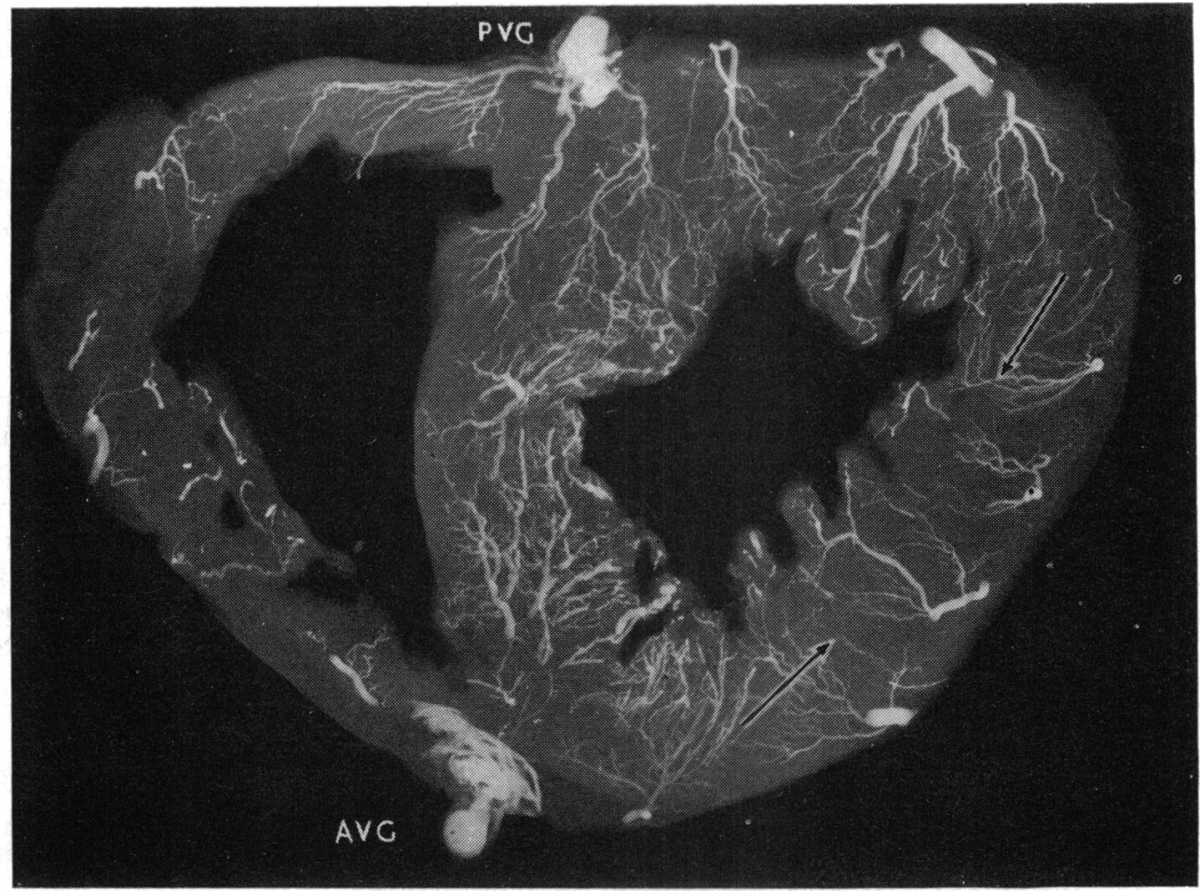

FIG. 1 Case 1. Radiograph of slice through ventricles viewed from above. Posterior vein graft (PVG) communicates with branches of posterior descending artery. Anterior graft (AVG) has leaked during post-mortem injection. There are prominent anastomoses in interventricular septum, with large subendocardial vessels. Anterolateral part of left ventricle (lower right quadrant) shows deficient vascular filling (between arrows), corresponding with infarcted area noted at operation and confirmed histologically.

circumflex branch of the left coronary artery was moderately atherosclerotic, with only a little narrowing, and supplied the posterior descending artery which was patent also. The anterior descending branch of the left coronary artery was very severely narrowed by atherosclerosis near its origin, and the minute lumen was discovered only by microscopy. No thrombi were found in any coronary arteries. The vein grafts were patent throughout. The infarct noted at operation was visible in the post-mortem angiogram as a zone of deficient vascular filling in the anterolateral wall of the left ventricle (Fig. 1); this corresponded with the infarct observed at operation. No changes could be found in the haematoxylin and eosin sections because the infarct was so recent; however, infarction was shown successfully by HBFP stain. The injection and fixation technique precluded the use of enzyme methods. There was a fibrous scar in the interventricular septum.

Transverse histological sections of the coronary arteries immediately proximal and distal to the graft insertions showed the following internal diameters: anterior descending artery, proximal to graft insertion $1.08 \mathrm{~mm}$, distal $0.91 \mathrm{~mm}$; posterior descending artery, proximal to graft insertion irregular and less than $0.9 \mathrm{~mm}$, distal $0.57 \mathrm{~mm}$. Some allowance should be made, in interpreting these figures, for tissue shrinkage in histological processing. Sections of the vein grafts showed no abnormalities.

The lungs were oedematous (left $700 \mathrm{~g}$, right $675 \mathrm{~g}$ ), and in the stomach there was a peptic ulcer.

Comment The patient's angina was almost totally incapacitating and was unresponsive to medical treatment. Pathologically there was very severe atherosclerotic narrowing of the ostia of both left and right coronary arteries, and of the anterior descending artery. Myocardial infarction occurred during coronary angiography, probably because of the ostial disease, and the patient died in spite of emergency vein grafting. Post-mortem coronary angiography showed patent vein grafts and poor 
vascularity of the anterior left ventricular wall, and staining for recently infarcted muscle was positive.

\section{Case 2}

A man of 55 years suffered from angina for 5 years and an attack of myocardial infarction occurred 3 years before death. During the last year of his life he had severe angina and dyspnoea on only slight exertion. Examination showed signs of advanced aortic valve disease, and coronary angiography showed a block in the anterior descending artery. At operation, the aortic valve was replaced and an aortocoronary vein graft was inserted into the anterior descending artery. The left coronary ostium was large and easily perfused, but the right coronary ostium was too narrow for cannulation at operation. The aortic valve cusps showed 'floppy valve' disease. There was fibrosis of the left ventricular myocardium. The heart arrested several times during the postoperative period and he died

\section{8 days later.}

The heart only was examined at necropsy and weighed $505 \mathrm{~g}$. A pink polypoid recent ante-mortem thrombus lay in the narrowed ostium of the right coronary artery. A cannula was inserted with ease into the left coronary artery but with difficulty into the right. The whole length of the vein graft to the anterior descending artery contained thrombus. In the post-mortem angiograms, the right coronary artery was filled irregularly with injection mass and was blocked completely near its junction with the posterior descending artery (Fig. 2); dissection showed atherosclerotic calcification with severe narrowing at this point, and there was thrombus partly filling the lumen of much of the main vessel proximally and blocking it at the site described above; the posterior descending artery was very narrow. The left main coronary artery was also atherosclerotic and the anterior descending branch was narrowed to $1 \mathrm{~mm}$ at a point about $3 \mathrm{~cm}$ above

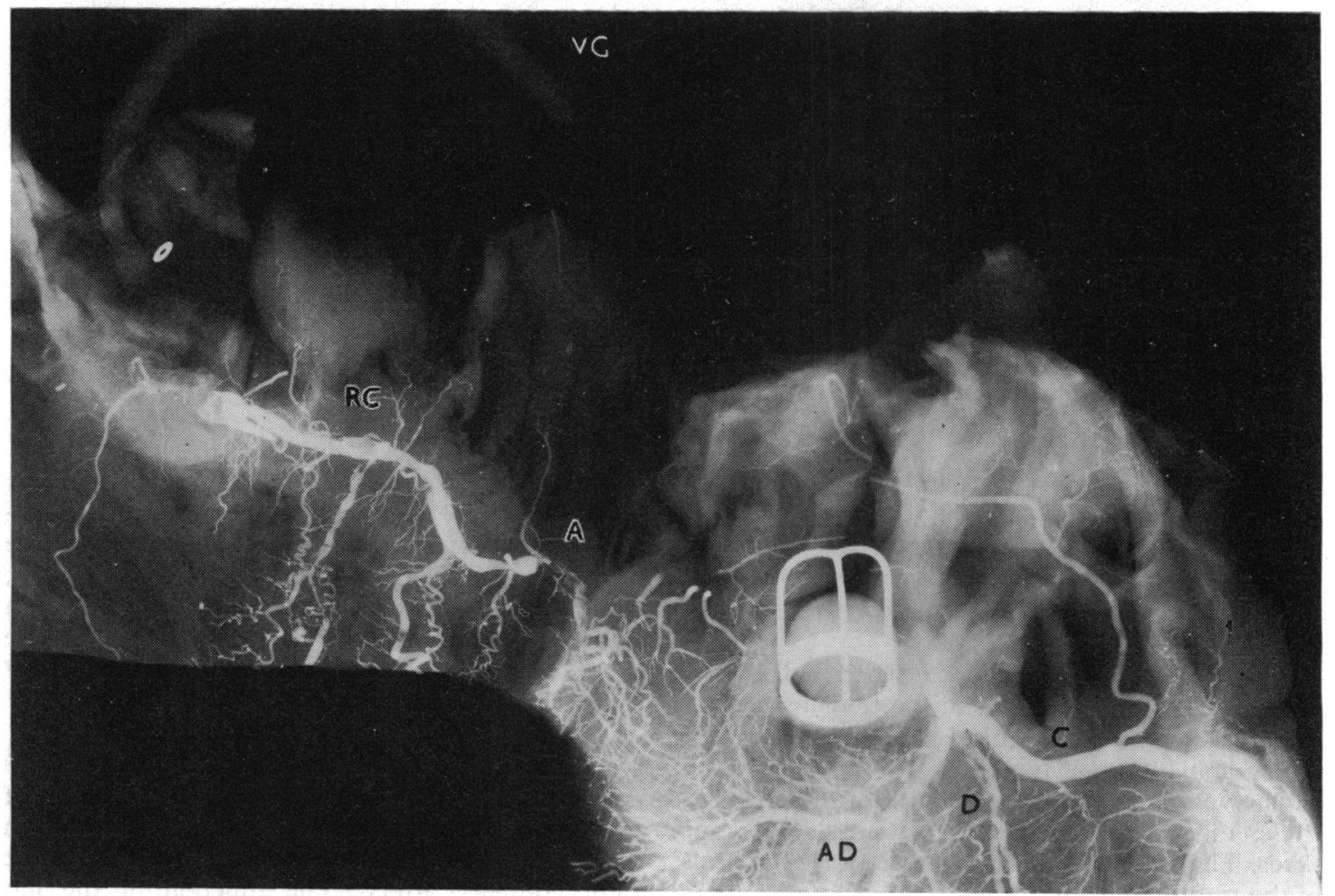

FIG. 2 Case 2. Radiograph of 'unrolled' heart with right ventricle to left. Prosthesis replaces aortic valve. Right coronary artery $(R C)$ is irregularly narrowed by atherosclerosis and partial thrombosis, and is blocked $(A)$ where it joins posterior descending artery. Occluded vein graft, with distal end cut, has been moved upwards $(V G)$. Narrowing of anterior descending artery $(A D)$, and diagonal branch $(D)$. Circumflex artery $(C)$ is only mildly atheromatous. See also Fig. 3. 


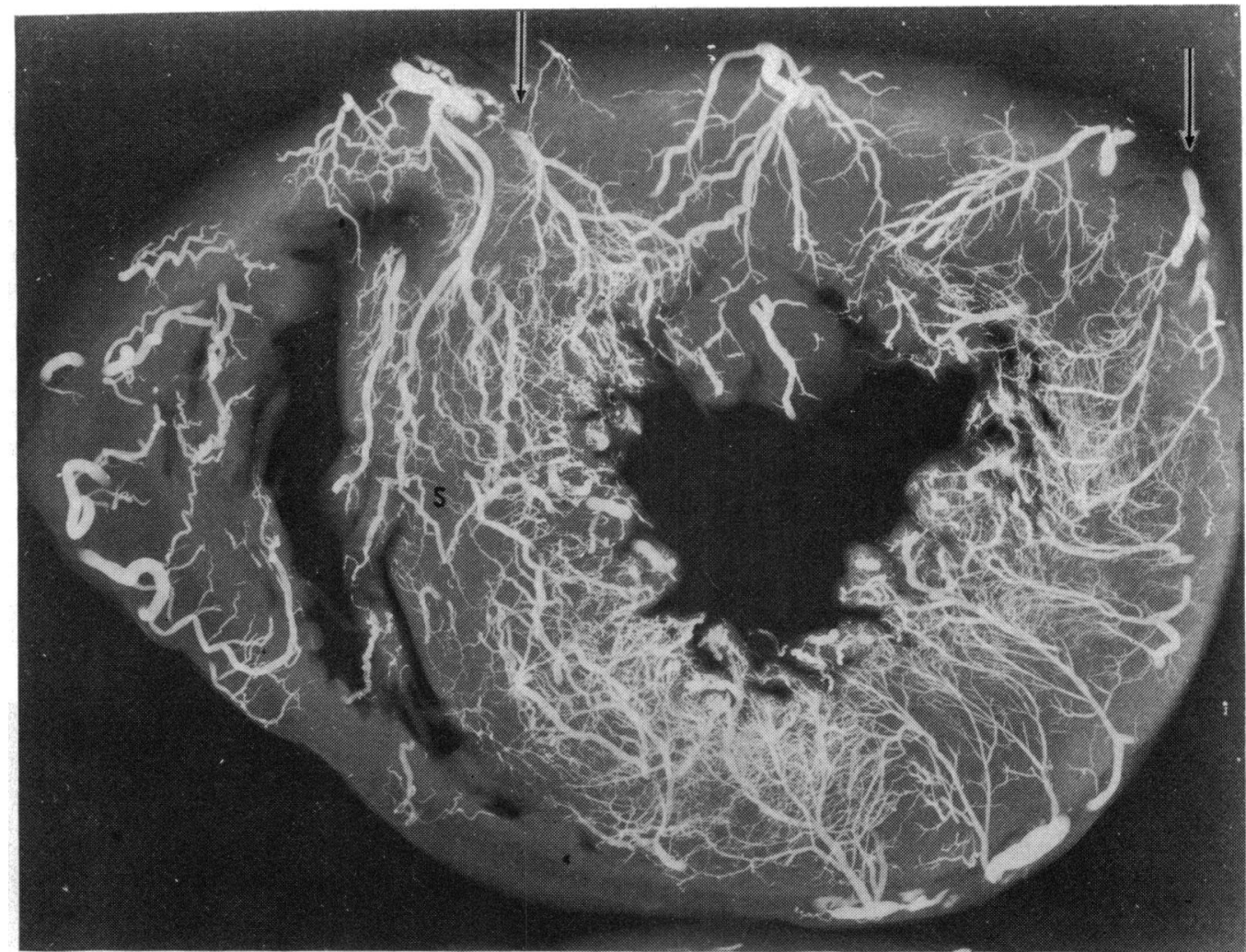

FIG. 3 Case 2. Radiograph of slice through ventricles showing deficient vascular filling in infarcted posterior wall of left ventricle (between arrows) in territory of recently thrombosed right coronary artery. Note hypertrophic thickening of left ventricle and prominent anastomoses in interventricular septum $(S)$.

the vein graft. There was a band across the lumen of the left circumflex branch near its distal end, indicating previous thrombosis, but no acute lesion was found and the vessel elsewhere showed only mild atherosclerosis. A diagonal artery was severely narrowed.

The left ventricle was hypertrophied and showed severe ischaemic fibrosis of its posterolateral part; there was also extensive fibrosis of the septum. In radiographs, most of the slices showed poor filling of fine vessels in the posterior wall of the left ventricle (Fig. 3), and in the lateral wall also in some slices. These changes were attributed to thrombosis of the right coronary artery.

Histologically, the anterior descending artery was atheromatous near the graft and measured $1.37 \mathrm{~mm}$ internal diameter proximally and $1.07 \mathrm{~mm}$ distally. The thrombus at the mouth of the right coronary artery showed platelet laminae, and was not organized; a similar thrombus was seen in sections of the same vessel further along. The thrombus in the vein graft to the anterior descending artery was cup-shaped and laminated near the aortic end, as if formed in a moving blood stream, while further down it had the appearance of a simpler static clot. Sections of the left ventricle showed fibrosis and early infarction, and the HBFP stain was positive.

Comment This patient with severe angina died 8 days after aortic valve replacement and insertion of vein graft into the anterior descending artery. Death was the result of thrombosis of the graft and of the right coronary artery. The function of the left ventricle was adversely affected by three factors, viz. recent infarction, scarring from previous infarctions, and possibly altered dynamics caused by aortic valve replacement. The thrombosis of the right coronary artery resulted from severe atherosclerosis at several sites but especially at the ostium 
which not only slowed blood flow, but also prevented this vessel from being perfused during the operation. The cause of thrombosis in the vein graft was not certain, though the run-off vessels were atheromatous and rather narrow.

\section{Case 3}

A man of 59 years had an attack of myocardial infarction 19 months before death and subsequently developed a left ventricular aneurysm, for which surgery was required. A coronary angiogram showed severe stenosis of the origin of the right coronary artery. At operation the aneurysm was resected and a vein graft was inserted into the right coronary artery. Early postoperative blood loss was controlled with a transfusion of fresh blood. Infection of the lungs and of a wound haematoma complicated convalescence and he died suddenly 3 weeks after operation, despite defibrillation.

Only the heart was available for study; it weighed $605 \mathrm{~g}$ and was covered by brown adhesions which held the vein graft lightly to the surface of the heart. The vein graft was patent. The suture line in the left ventricle was satisfactory. The orifices of coronary arteries were narrow; when the mass was injected into them using fine cannulae, it returned up the vein graft, which was then ligated at the aortic end to conserve injection pressure.

Radiography and dissection of the heart showed that beyond the ostial stenosis, the right coronary artery was widely patent, and there was a wide opening into the graft; there was some narrowing of the posterior descending artery at one point. The left coronary artery was also narrowed at its origin, and there was very severe atherosclerosis of the anterior descending, circumflex, and diagonal branches. There was deficient vascularization of part of the left ventricle in the radiograph of the 'unrolled' specimen (Fig. 4). On dissection, the left ventricle showed extensive ischaemic fibrosis of the lateral and posterior walls, involving much of the endocardium and also some of the papillary muscles (aneurysm resected surgically). Mural thrombus was present. About one-third of the muscle of the

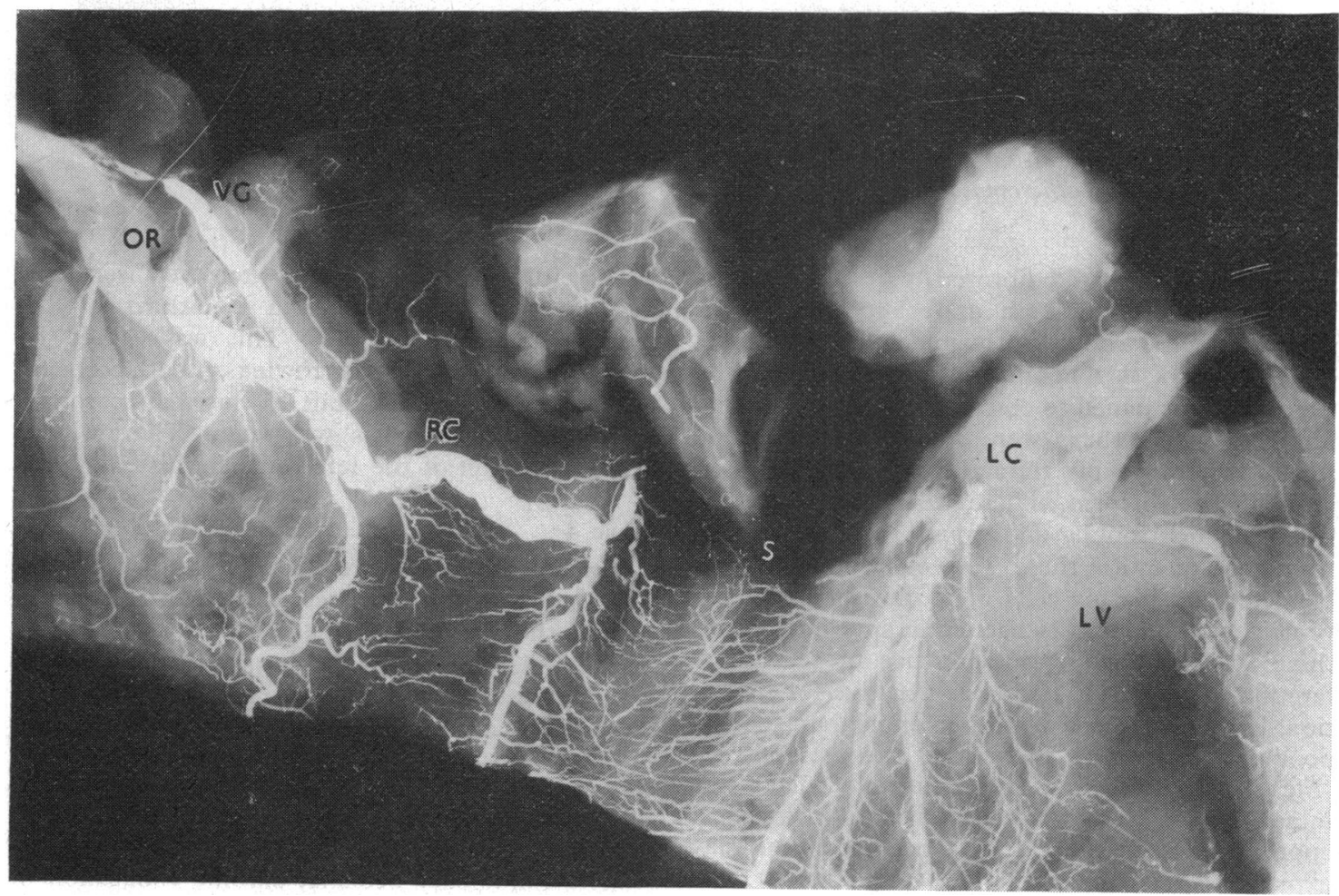

FIG. 4 Case 3. Radiograph of 'unrolled' heart with right ventricle to left. Vein graft (VG) is patent and supplies broad right coronary artery $(R C)$ which was narrowed near its origin (OR). Conspicuous septal anastomoses $(S)$. Left coronary artery $(L C)$ and branches are severely narrowed and much of left ventricle shows deficient vascularization (LV). 


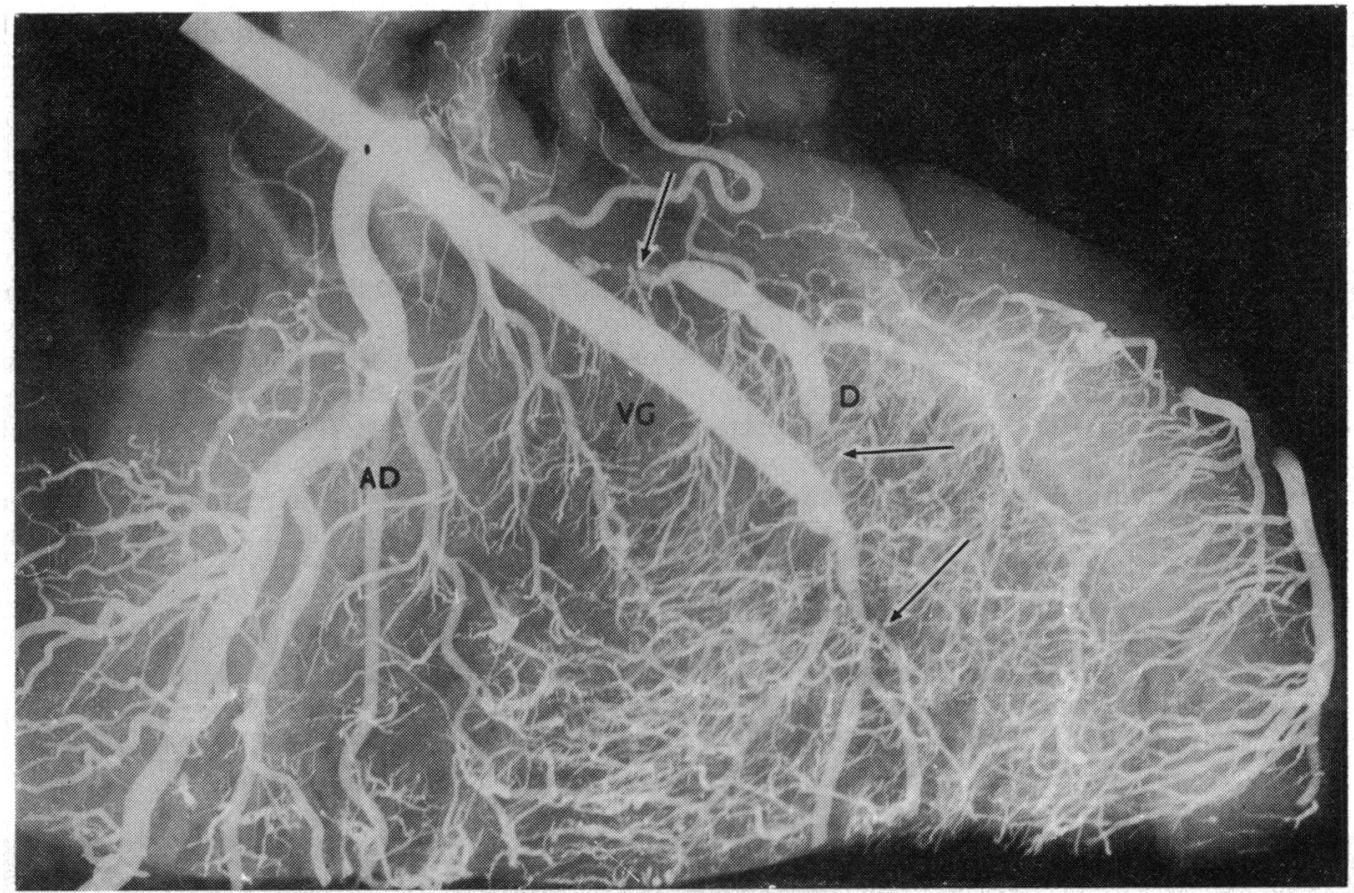

left ventricle appeared fibrosed.

Histologically, the vein graft appeared patent and was lined by a layer of viable endothelial cells. The media was viable and slightly thickened. The adventitia was joined to epicardial fat by organizing fibrin in which there were small foreign bodies, some of them doubly refractile, which had caused granulomata to form. There were also small collections of neutrophils, and around vessels some way from the adventitia there were collections of lymphocytes and plasma cells. The fibrosis of the left ventricle was old and ischaemic in appearance, and there was no histological evidence of recent infarction. The HBFP stain was negative for infarction. However, the post-mortem angiogram showed poor perfusion of a wide area of the left ventricle (Fig. 4), suggesting greater ischaemic effects terminally than was evident from the histological appearance of the muscle. This poor perfusion may explain his sudden irreversible cardiac arrest.

Comment As far as can be made out from pathological examination of the heart alone, the cause of death three weeks after operation was failure of the left ventricle caused by extensive ischaemic fibrosis involving more than one-third of the muscle (aneurysm excised). This was caused by multiple atherosclerotic narrowings of both coronary arteries. A single vein graft to the right coronary artery (for ostial stenosis) was patent. There was no acute infarction of the left ventricle histologically.

\section{Case 4}

A man of 59 years suffered from angina of effort for 10 years, and this had become increasingly severe during the previous year. Coronary angiography showed stenoses of the right coronary artery, and poor filling of the left circumflex artery. Vein grafts were inserted into the right coronary artery and lateral branch of the left circumflex coronary artery, but on the day after operation, he became unconscious, and remained so until death 10 days later.

Necropsy showed cerebral oedema and haemorrhages, pulmonary oedema, chronic congestion of the liver, and prostatic enlargement. The heart weighed $380 \mathrm{~g}$ and was covered by brown adhesions. Both grafts were patent. When medium was injected into the vein graft to the right coronary artery it 
returned up that artery, which was. then ligated to conserve pressure. Similarly, injection of the vein graft to the lateral branch of the left circumflex coronary artery was followed by reflux from the left main coronary artery, which also was ligated.

Dissection and radiography showed extensive atherosclerosis of the coronary arteries receiving the grafts which would probably have limited their usefulness had the patient lived longer. The internal diameter of the right coronary artery was narrowed to $2 \mathrm{~mm}$ proximal to the vein graft and to the same extent at a point about $1 \mathrm{~cm}$ distal to the graft. The left main coronary artery was widely patent, but the lumen of the lateral circumflex artery was reduced to $1 \mathrm{~mm}$ in diameter immediately proximal to the graft entrance, to about $0.5 \mathrm{~mm}$ at a point $3 \mathrm{~cm}$ proximal, and to a similar extent $1.5 \mathrm{~cm}$ distal to it (Fig. 5). The anterior and posterior descending arteries were less atheromatous. The fine left ventricular vessels were well filled with medium. The lateral wall of the left ventricle was scarred from apex to base, associated with the severe atherosclerosis of the lateral circumflex artery. Histolo- gically, the grafts were viable and the endothelium was intact; the intima showed a trace of thickening.

Comment The patient suffered from severe angina for 10 years. He died 10 days after operation from cerebral changes. Both vein grafts were patent at necropsy. Severe coronary disease was present both proximal and distal to the anastomoses, and there was ischaemic fibrosis of part of the left ventricle.

\section{Case 5}

A woman of 65 years suffered from angina for 8 years, becoming worse latterly. Aortic valvular stenosis was present. Coronary angiography showed several major stenoses of the right coronary artery and some less severe stenoses of both branches of the left coronary artery. At operation, a vein graft was inserted into the right coronary artery and an aortic valvotomy was performed. The vein graft was turned inside out to remove valves so that the smaller end could be inserted into the coronary artery. Subsequently there was only slight improvement in the

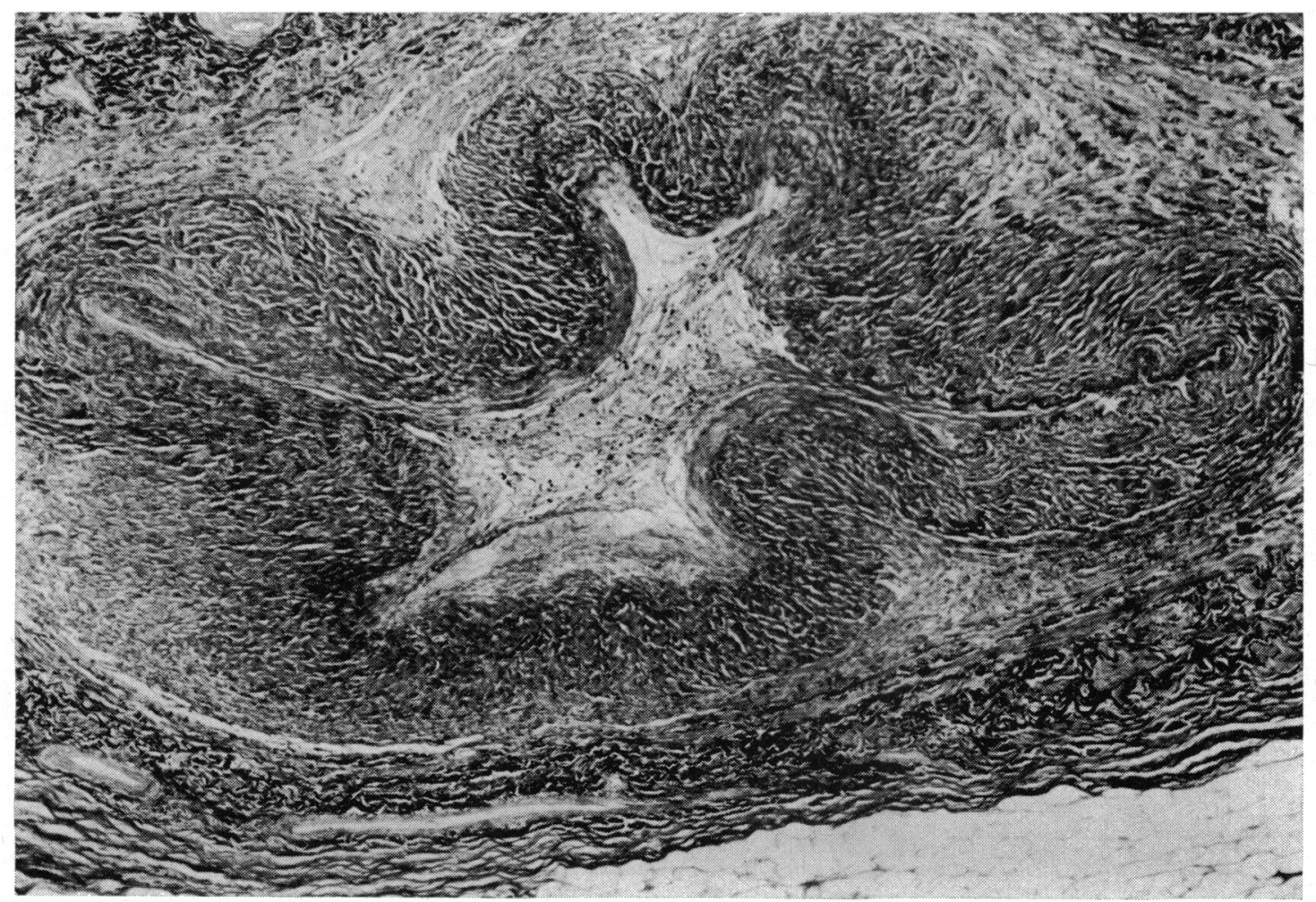

FI G. 6 Case 5. Veingraft showing old occlusion of lumen by delicate connective tissue containing siderotic histocytes seen as small dots. Corrugations of media result from inward collapse of graft. (Elastic-van Gieson. $\times 55$.) 
angina, and the patient died in heart failure 6 months later.

At necropsy, the vein graft to the right coronary artery was found to be collapsed and was occluded completely by pale tissue. (No medium was injected into the coronary arteries because of an accidental cut in the wall of the right ventricle.) The ostium and main stem of the right coronary artery showed severe narrowing by atherosclerosis. The left main coronary artery was widely patent, but the first $5 \mathrm{~cm}$ of the anterior descending artery was calcified and extremely narrow, and the left circumflex artery was very narrow at a point $3 \mathrm{~cm}$ from its origin; the severity of the disease seemed to have increased since the cineangiogram 6 months previously. The left ventricle was $15 \mathrm{~mm}$ thick, and showed a small focus of fibrosis in the anterior wall, involving papillary muscles. There was calcific aortic valve disease (treated by valvotomy). Pulmonary oedema and 'nutmeg' liver were the main changes in other organs.

Histologically, old organized thrombus filled the lumen of the graft (Fig. 6), and there were some siderotic histiocytes in the small amount of dense organizing connective tissue present. The intima showed fibroelastic thickening, and was corrugated and collapsed inwards. Suture material and other foreign matter were present in the adventitia, causing the formation of reactive granulomata. A section of left ventricle showed recent infarction as well as old fibrosis. The HBFP stain was positive for infarction. No recent thrombi were found in sections of coronary arteries.

Comment This woman died from the effects of very severe atherosclerotic narrowing of all 3 principal coronary arteries, and aortic valve disease. A vein graft, inserted into the right coronary artery at the time of aortic valvotomy 6 months previously, was found to be occluded, having thrombosed probably shortly after operation. There was a fresh infarct of the left ventricle terminally.

\section{Case 6}

A man of 49 years had two attacks of praecordial pain, 7 and 3 weeks before death. An electrocardiogram showed evidence of an anterior myocardial infarction, and he developed congestive cardiac failure. Infarctectomy was considered and a coronary angiogram was performed. This showed complete

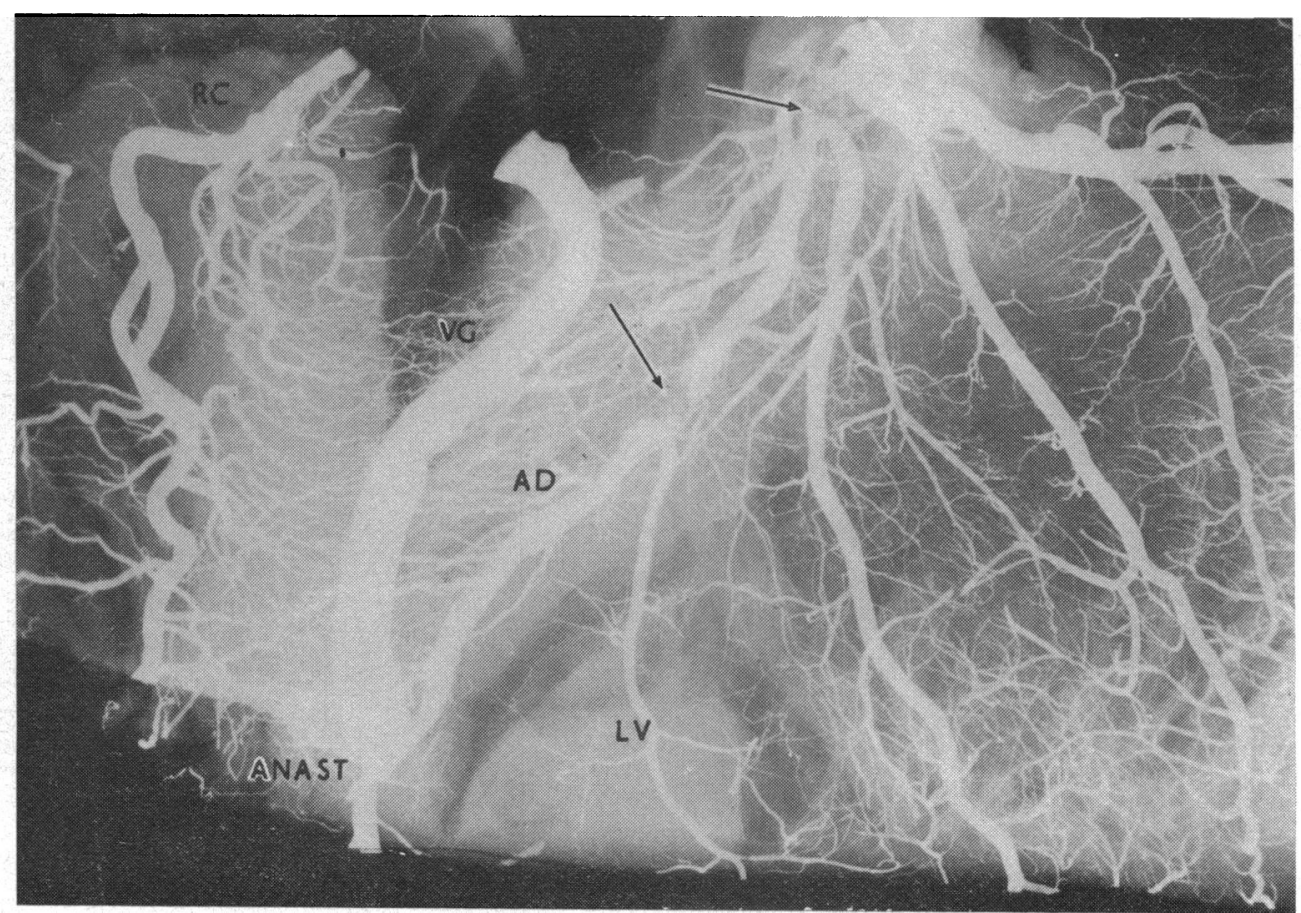

FI G. 7 Case 6. Radiograph of 'unrolled' heart with right ventricle to left. Vein graft (VG) is patent and supplies left anterior descending artery $(A D)$ which is severely narrowed at 2 sites (arrows) and near anastomosis (ANAST) by continuous thrombus. Infarcted part of left ventricle is poorly vascularized ( $L V)$, and shadow of large mural thrombus can be seen. 
occlusion of the left anterior descending coronary artery near its origin, with retrograde filling from the right coronary artery which was also diseased. At operation, a vein graft was inserted into the anterior descending artery, but the infarct was found to be unsuitable for excision. He died 5 days later.

At necropsy the heart weighed $545 \mathrm{~g}$. Medium was injected into the graft and into the left coronary artery. The ostium of the right coronary artery was too narrow to take a thin cannula, but medium appeared from it retrogradely during injection, and it was ligated to raise the pressure within.

Radiographs and dissection showed a dominant left and a small right coronary artery. There was poor vascularization of part of the left ventricle in $x$-ray films (Fig. 7). The ostium and first $3 \mathrm{~cm}$ of the right coronary artery were severely narrowed by atheroma to about $1 \mathrm{~mm}$ internal diameter. There was a large plaque narrowing the left main coronary artery; the circumflex and posterior descending arteries were only slightly diseased, but the anterior descending artery was severely narrowed by calcified atheroma and a retracting organizing thrombus extended from the origin of the vessel to the graft insertion, leaving the lumen only just patent to medium. Histologically, the thrombus appeared about 2 weeks old; just proximal to the anastomosis it formed a thin band running across the lumen. The vein graft was patent, and so was the distal part of the recipient artery which measured $2 \mathrm{~mm}$ in internal diameter. Histologically, the wall of the vein appeared well preserved (Fig. 8) and there was no intimal thickening. The left ventricle showed a combination of extensive fibrous scarring and recent infarction to involve two-thirds of its circumference, including part of the septum. There was a large mural thrombus within the left ventricle. Histologically, one infarct appeared about 2 months old, and the other about 7 to 10 days old.

The only other necropsy finding was an infarct in the right lower lobe of lung, and there were emboli in smaller pulmonary arteries (less than $7 \mathrm{~mm}$ in diameter).

Comment This patient died 5 days after a vein graft operation for advanced ischaemic heart

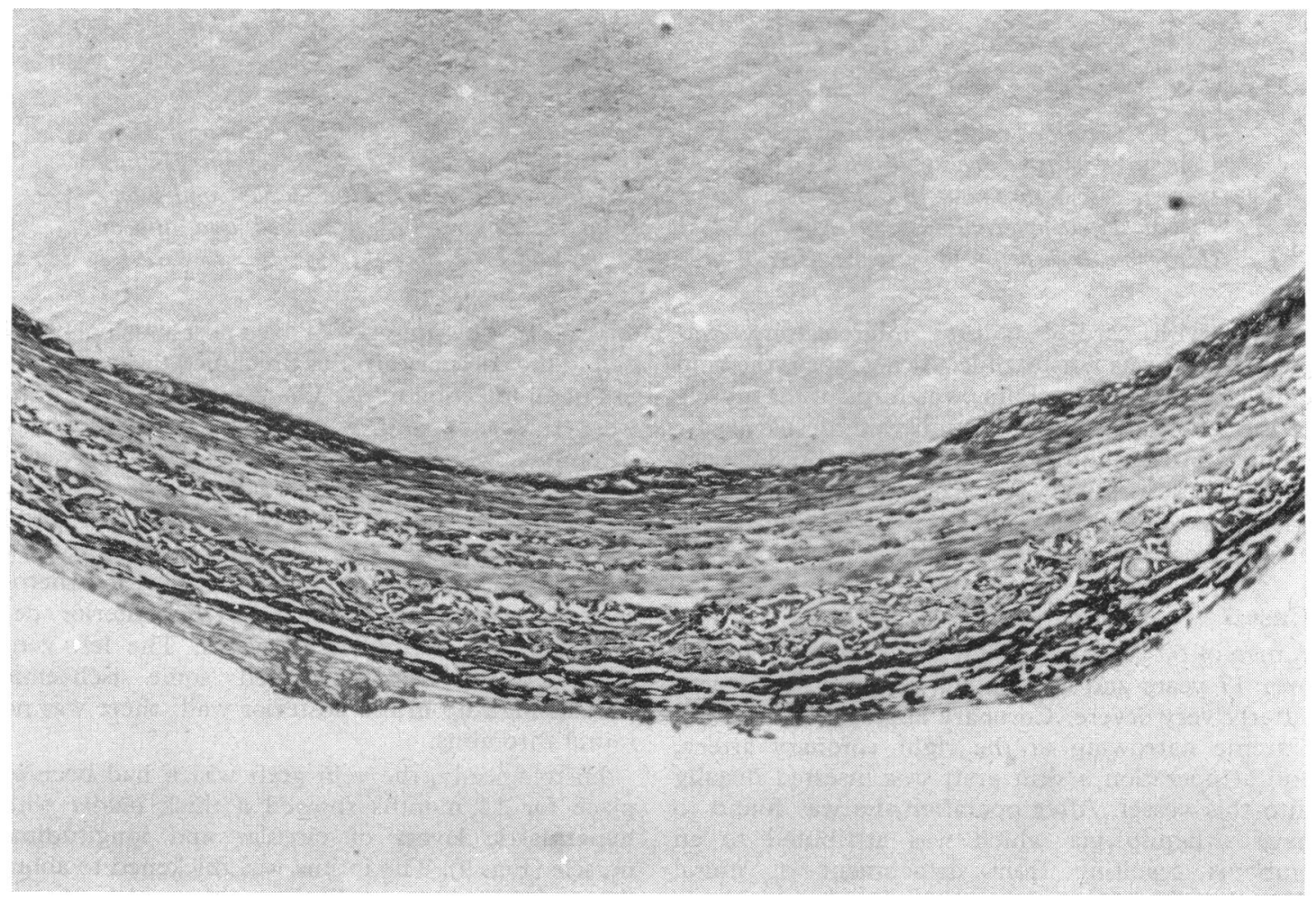

FIG. 8 Case 6. Transverse section of patent vein graft 5 days after operation. Vessel wall is distended by injection medium seen in upper half of field. The wall appears well preserved. Compare with Fig. 9. (Elastic-van Gieson. $\times 55$.) 


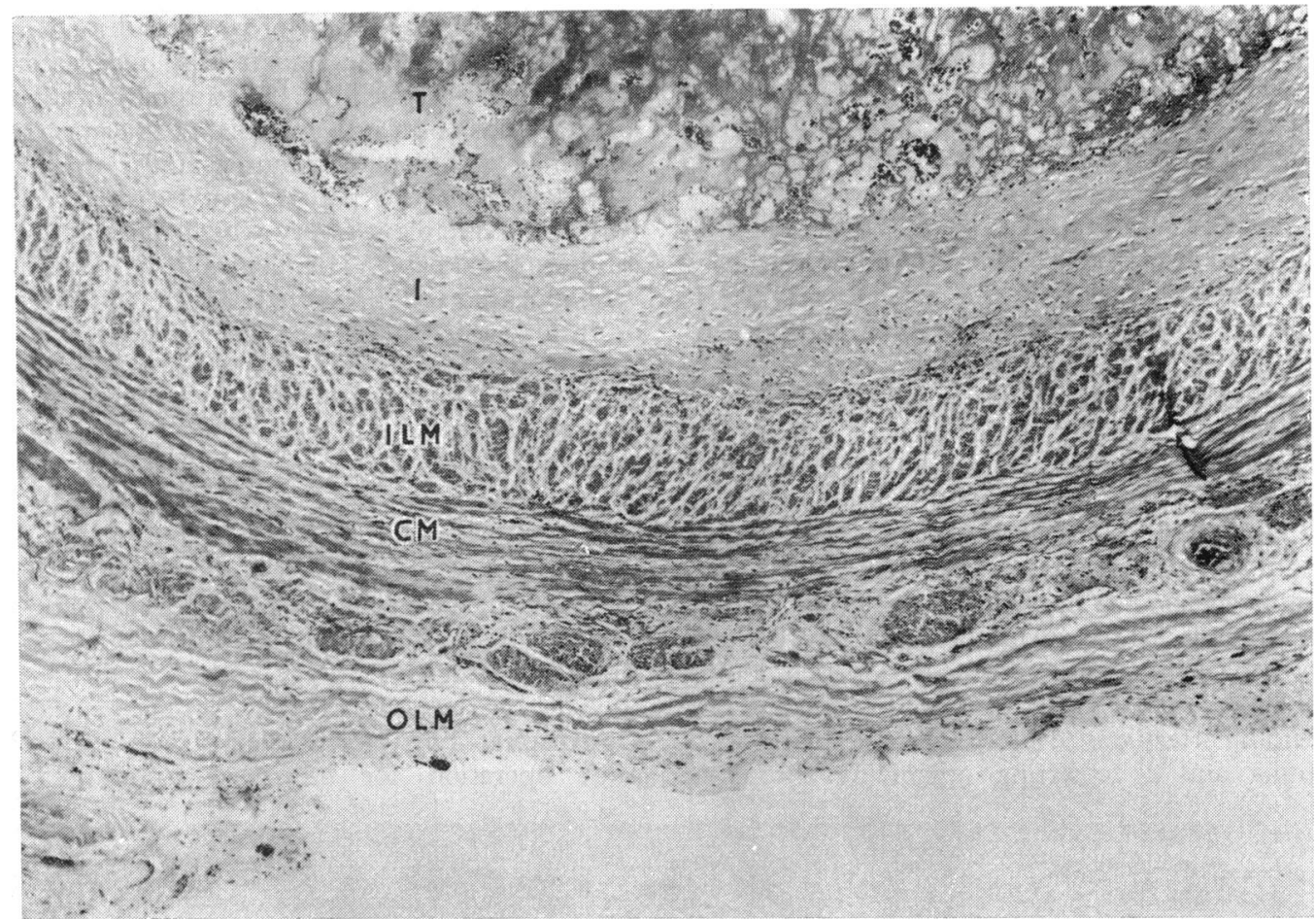

FIG. 9 Case 7. Transverse section of vein graft from patient who died 13 months after operation. Compared with younger graft in Fig. 8, inner part of wall $(I)$ is thickened by dense collagen and there is recent thrombus in lumen (T). Inner longitudinal (ILM), circular (CM), and interrupted outer longitudinal (OLM) muscle layers of media are well preserved and appear thickened in response to systemic arterial pressure. (H. and E. $\times 55$.)

disease with cardiac failure; infarctectomy was planned but was not feasible. At necropsy, the vein graft was patent, but about two-thirds of the muscle of the left ventricle and septum were destroyed by infarcts antedating the operation. Small pulmonary emboli were present. The disease of the left ventricle appeared in retrospect to be too extensive to benefit from revascularization.

\section{Case 7}

A man of 60 years had had 6 acute coronary attacks over 17 years and also angina of effort which was latterly very severe. Coronary angiography showed extreme narrowing of the right coronary artery, and at operation a vein graft was inserted distally into this vessel. After operation, he was found to have a hemiplegia which was attributed to an embolus resulting from detachment of mural thrombus from the left ventricle. He died suddenly 13 months after operation.

At necropsy, the heart which was received fixed in formalin was covered by dense postoperative adhesions. The presence of fixed post-mortem blood clot in the coronary arteries precluded the successful use of an injection mass. The walls of the vein graft were thickened and the lumen was blocked by thrombus, which was pale brown proximally and dark reddish-brown distally; the right coronary artery was extremely narrow proximal and distal to the anastomosis. The left main coronary artery was widely patent, but there was severe atherosclerotic narrowing of parts of the anterior descending and circumflex branches. The left ventricle $(1.2 \mathrm{~cm}$ thick) showed some ischaemic fibrosis high up in the posterior wall; there was no mural thrombus.

Histologically, the vein graft which had been in place for 13 months showed a thick media with hyperplastic layers of circular and longitudinal muscle (Fig. 9). The intima was thickened to about $0.3 \mathrm{~mm}$ by dense collagen with widely-spaced fibrocytes that were more numerous away from the lumen. The lumen in proximal sections was filled with fairly recent thrombus, containing degenerat- 


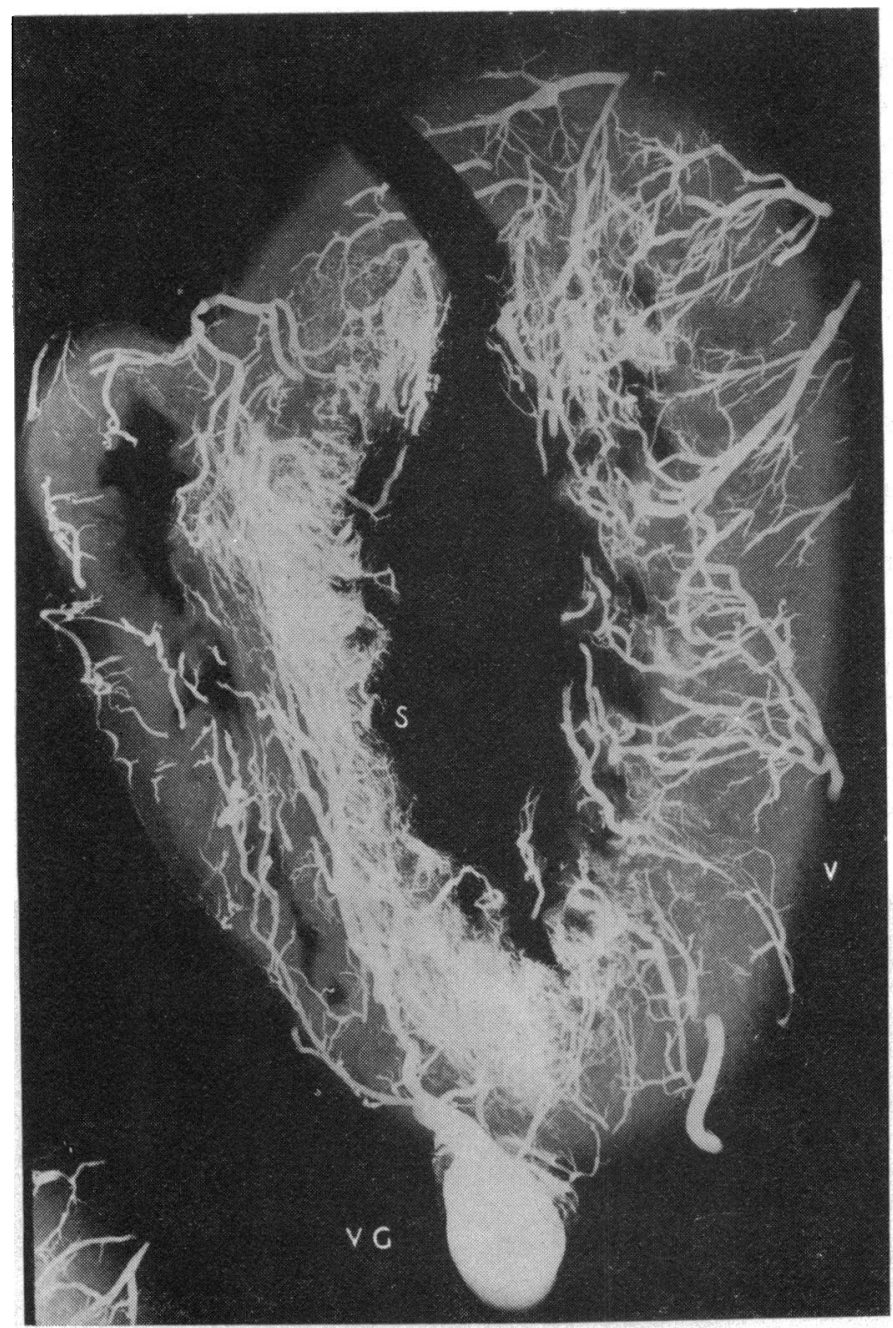

FIG. 10 Case 8. Radiograph of slice through ventricles showing patent anterior vein graft (VG) communicating with anterior descending artery and branches, including numerous septal anastomoses $(S)$. Slightly deficient filling of vessels in left ventricular wall at $V$.

ing red cells and compact fibrin, and becoming organized from the intima. There was a light infiltrate of lymphocytes and plasma cells in a few foci near the junction of adventitia and adjacent adipose tissue. In the intima near the thrombus there were a few foamy phagocytes slightly resembling atheroma, and also some siderotic histiocytes. In the lumen of the graft distally there was more recent thrombus containing intact red cells and showing no signs of organization. Sections of the left ventricle showed ischaemic fibrosis and no evidence of infarction; the HBFP stain was negative.

Other necropsy findings (kindly provided by
Dr. H. de C. Baker, Norfolk and Norwich Hospital) included a large old infarct of the left temporal lobe of the brain and oedema of the lungs.

Comment This man died 13 months after operation for severe angina. There was severe atherosclerosis of all 3 principal coronary arteries and a vein graft was inserted into the worst affected right coronary artery. At necropsy, the vein graft showed narrowing caused by intimal fibrosis, and blocking of the lumen throughout its length by thrombus of short duration. 


\section{Case 8}

A man of 55 years had had angina of effort for 11 years, becoming severe latterly. A coronary angiogram showed severe narrowing of the right coronary artery with retrograde filling of its distal portion from the circumflex artery. There were also severe narrowings of the anterior descending and circumflex branches of the left coronary artery. Vein grafts were inserted into the anterior and posterior descending arteries, but measured blood flow through the grafts was very slow. The left ventricle would not pump effectively, and he died shortly after the operation.

Necropsy showed pulmonary embolism, with complete obstruction of the right main pulmonary artery by a coiled embolus from a leg vein, $12 \mathrm{~cm}$ long when unfolded. The heart weighed $365 \mathrm{~g}$, and when medium was injected first into the anterior descending vein graft, it returned from both coronary arteries and from the posterior descending vein graft. The ostia of the coronary arteries were too narrow to inject, and were ligated to maintain pressure during injection of the grafts. Because the aortic end of the posterior descending vein graft was narrow, medium was injected through an incision further down the graft.

Dissection and radiographs confirmed the patency of the grafts. The communication of the vein graft with the anterior descending artery is illustrated in Fig. 10. There was an almost complete atherosclerotic block of the right coronary artery $3.5 \mathrm{~cm}$ from the origin. The left main coronary artery was moderately narrowed beyond the stenosed ostium. The lumen of the origin of the anterior descending artery was less than $1 \mathrm{~mm}$ in diameter. The circumflex artery was moderately narrowed and a lateral ventricular branch was blocked (Fig. 11) by a haemorrhage into a plaque, confirmed histologically. The posterior vein graft was patent and the recipient posterior descending artery was $2 \mathrm{~mm}$ in diameter. The left ventricle was normal in thickness $(14 \mathrm{~mm})$ and sections showed ischaemic fibrosis high in the posterior wall. In radiographs there was slightly reduced filling of vessels of the left ventricle (Fig. 10), though sections failed to show infarction and the HBFP stain was negative.

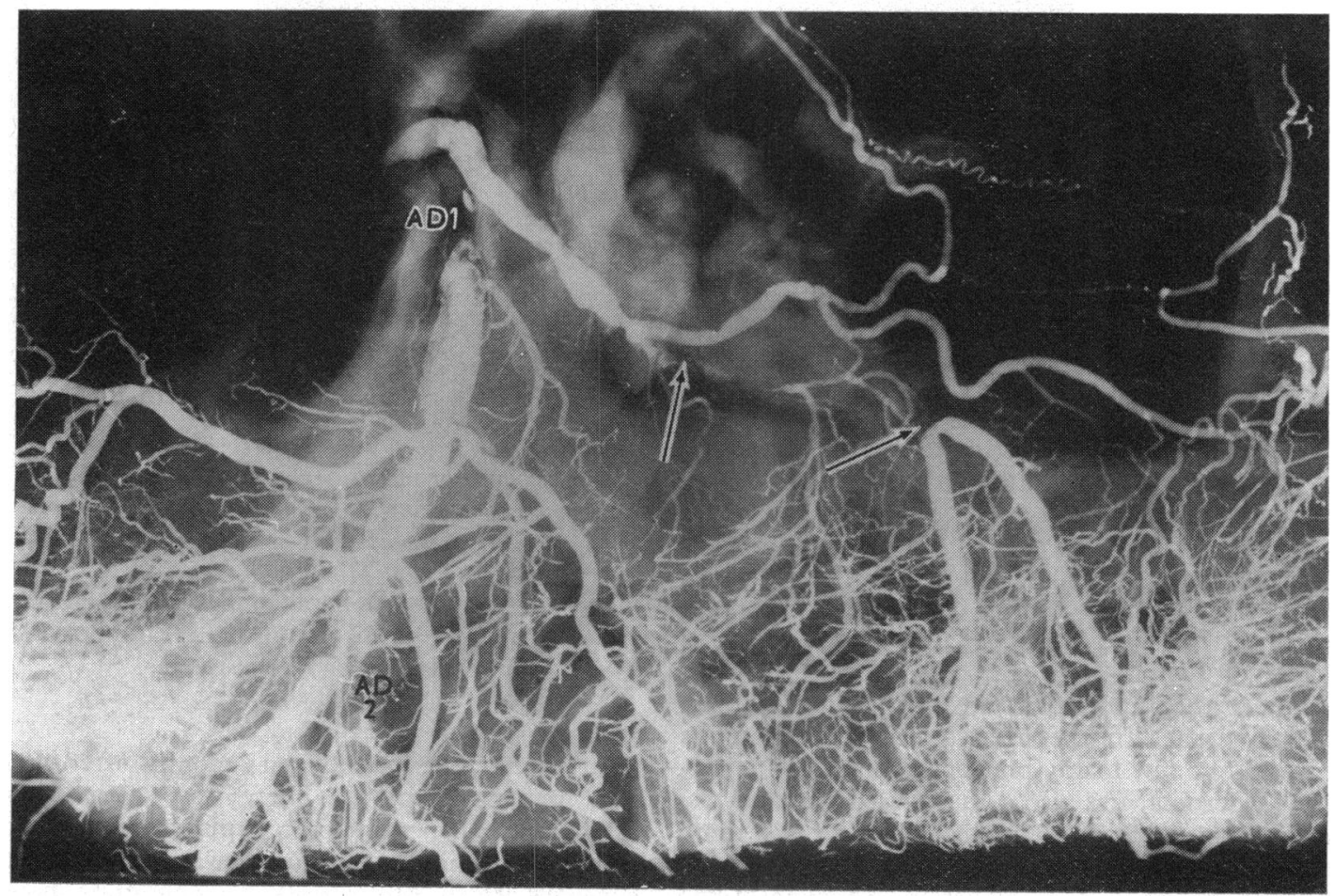

FIG. 11 Case 8. Radiograph of unfolded left ventricle. Severe atherosclerotic narrowing of anterior descending branch of left coronary artery in 2 sites ( $A D$ 1, AD 2). Large lateral branch of circumflex artery is blocked (between arrows) by haemorrhage into a plaque. 


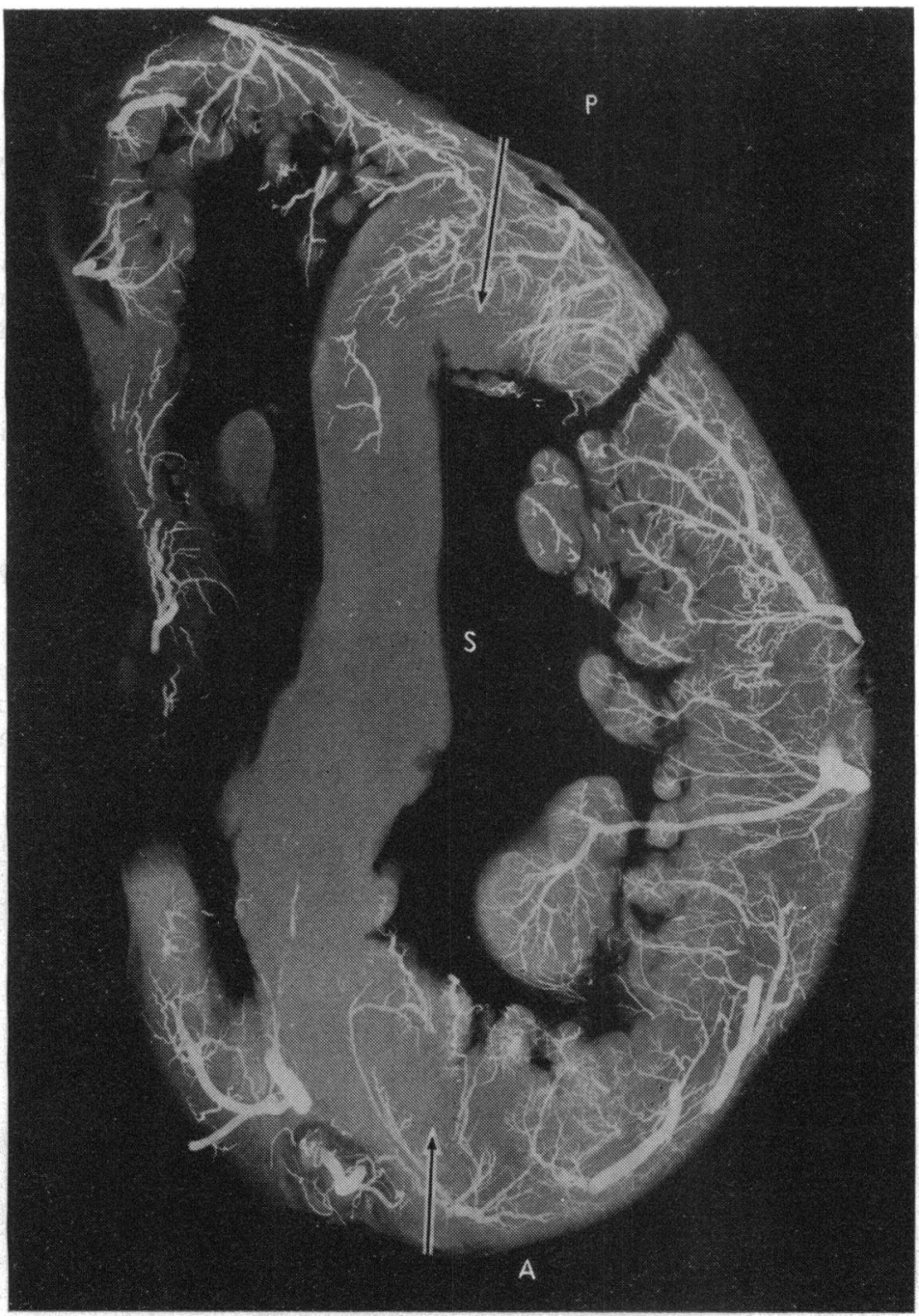

FI G. 12 Case 9. Radiograph of slice of ventricles. Infarction (between arrows) of interventricular septum $(S)$ is accompanied by almost completely deficient filling of vessels of most of septum and part of anterior $(A)$ and posterior $(P)$ walls of left ventricle.

Comment This patient died from massive pulmonary embolism occurring during a vein graft operation. He was operated on for angina of long duration, latterly disabling. There was severe narrowing of the ostia and other parts of both coronary arteries and also a haemorrhage into a plaque on the circumflex artery. The vein grafts were patent.

\section{Case 9}

A man of 41 years, with gout for 18 years, had had 2 attacks of myocardial infarction 13 and 2 months before death. Heart block followed the second illness. Coronary angiography showed occlusion of the anterior descending artery, and a major stenosis of the right coronary artery. A large part of the left ventricle was non-contractile. Operation was undertaken for excision of an aneurysm of the left ventricle, and a vein graft was put into the right coronary artery. He did not recover from the operation.

At necropsy, the heart weighed $475 \mathrm{~g}$. Medium injected into the patent vein graft returned from the narrowed orifice of the right coronary artery, 
which was then ligated. The left' coronary artery was also injected.

Dissection, radiographs, and histology showed narrowing of the lumen of the right coronary to $1 \mathrm{~mm}$ internal diameter at a point $3 \mathrm{~cm}$ from its origin (beyond the ligation), and also narrowing to $2 \times 1 \mathrm{~mm}$ distal to the graft insertion, with widening later. The left main coronary artery was moderately narrowed; the anterior descending artery was blocked by a haemorrhage into a plaque and new thrombus filling the small remaining lumen. The middle region of the circumflex artery was narrowed by atherosclerosis and blocked by an organizing thrombus. The interventricular septum showed extensive conspicuous yellow infarction of fairly recent occurrence, and there was fibrosis of the anterior and posterior walls (aneurysm excised), and other parts of the septum. There were small patches of ischaemic fibrosis in the right ventricle. The post-mortem angiograms showed almost complete absence of vessel filling in the infarcted septum and in parts of the anterior and posterior walls of the left ventricle (Fig. 12).
Other findings at necropsy were gouty deposits in a metatarsophalangeal joint, and infarcts in the right lung and right kidney.

Comment The great severity of the coronary artery disease and the resulting damage to the left ventricle were well appreciated before operation, but it was considered that vein grafting and aneurysmectomy offered the only hope for this relatively young patient. He did not recover from the operation. Pathologically, it was thought in retrospect that too much of the left ventricle had been destroyed before operation for benefit to result from surgery.

\section{Case 10}

A man of 51 years had had angina on exercise for 2 years and a myocardial infarct 9 months before death. Coronary angiography showed severe atherosclerosis of the right main coronary artery and of the origins of the anterior descending and circumflex branches of the left coronary artery. Vein grafts were inserted into the anterior and posterior de-

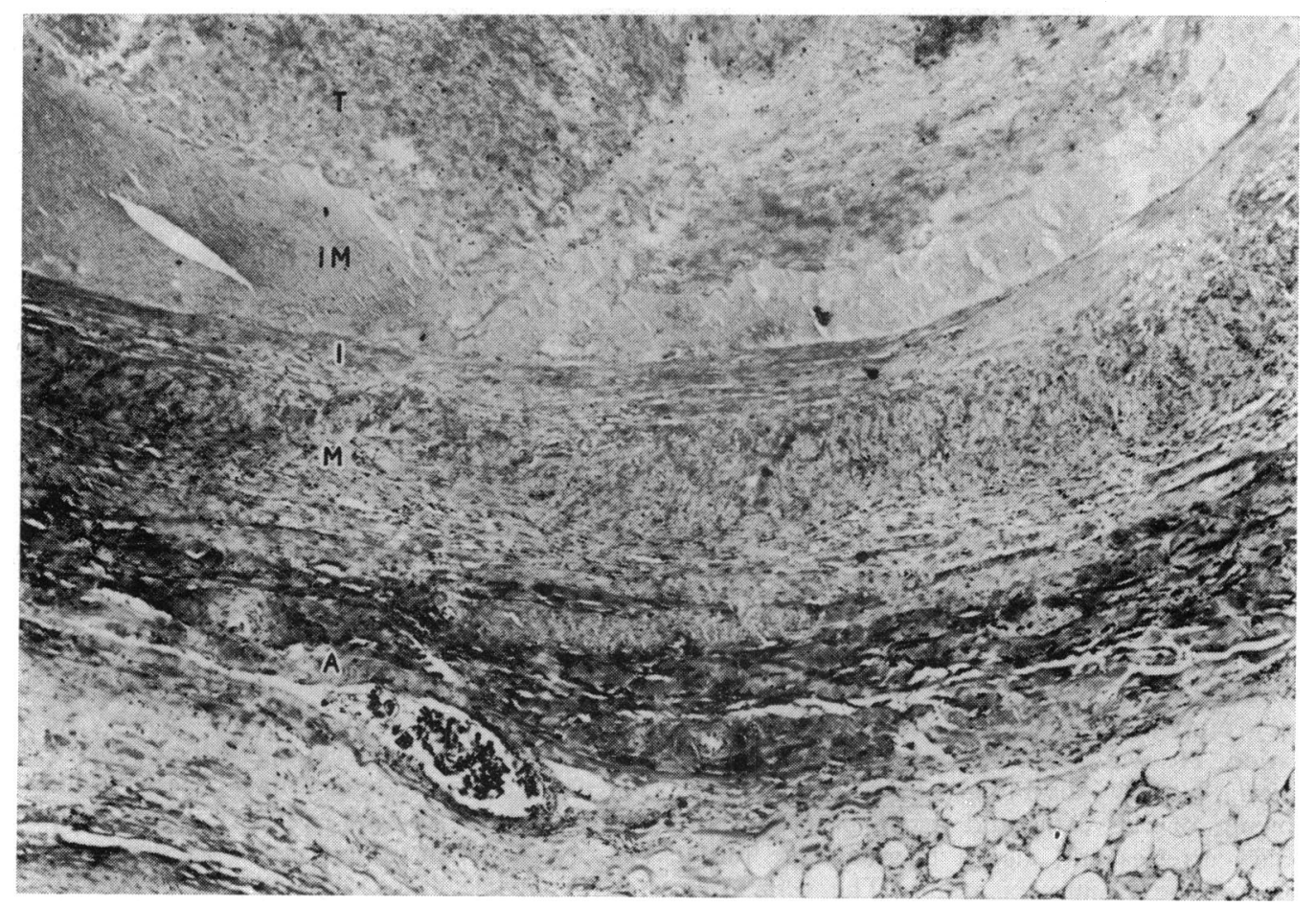

FIG. 13 Case 10. Transverse histological section of vein graft to posterior descending artery near anastomoses with that vessel. Thrombus (T) and small amount of injection mass (IM)

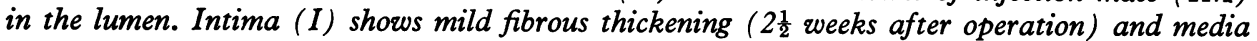
$(M)$ is also thickened (compare with the 5-day graft in Fig. 8). Suture material in adventitia at A. (Elastic-van Gieson. $\times 55$.) 
scending coronaries. Two and a half weeks later when recovery appeared well advanced, he suddenly collapsed and died from pulmonary embolism despite surgical embolectomy.

At necropsy, the heart weighed $585 \mathrm{~g}$. Medium injected into both coronary arteries returned slowly up the anterior vein graft, but not at all up the posterior graft. The aortic ends of both grafts were very narrow and could not be probed, though the corresponding openings in the aortic wall were wide.

Dissection, radiographs, and histology confirmed the patency of the anterior descending vein graft, but the graft to the posterior descending artery was blocked by an organizing thrombus stretching from the aortic and almost to the coronary end (Fig. 13). The recipient posterior descending artery was patent and measured $2 \mathrm{~mm}$ in internal diameter proximal to the anastomosis, and $1 \mathrm{~mm}$ distally. The right coronary artery showed moderate atherosclerosis and calcification. The left main coronary artery and its circumflex branch were similarly affected. The worst disease was in the anterior descending artery, which was not only thickened by intimal fibrosis and calcification, but almost completely blocked by a large haemorrhage into a plaque, accompanied by a small thrombus in the lumen. The vessel also contained a small amount of thrombus near the anastomosis, where it measured $2 \mathrm{~mm}$ in internal diameter, both proximal and distal to the anastomosis.

The left ventricle showed the anteroseptal infarct, nine months old. In the lungs there were very many emboli blocking medium-sized pulmonary arteries. Dissection of both femoral veins revealed many similar small thrombi.

Comment The patient died of pulmonary embolism two and a half weeks after a vein graft operation. There were thrombi in both femoral veins (not confined to the left leg from which the grafting vein had been taken). A vein graft to the anterior descending artery was patent. The recipient vessel showed a haemorrhage into a plaque proximally, plus thrombosis, and there was an anteroseptal infarct. A vein graft to the posterior descending artery seemed to have become blocked by thrombus soon after the operation, possibly because of a narrow aortic anastomosis.

\section{Discussion}

This pathological study indicates that death in 10 cases of severe coronary atherosclerosis occurring during early experience with aortocoronary saphenous vein bypass grafting was usually caused by the extreme severity of the coronary artery disease, and of its effects on the left ventricle. The 10 deaths occurred during a period when approximately 80 vein-grafting operations were performed, representing a mortality rate of 12.5 per cent, with a follow-up period of up to 13 months after operation. This high mortality in these early cases, compared with our own later experience (Balcon et al., 1974) and that of others, may be partly the result of the severity of coronary atherosclerosis.

The ostium of the left main coronary artery was severely stenosed in 3 of the 10 cases reported here. The left anterior descending artery was severely stenosed or occluded in 9 cases. The circumflex artery showed severe stenosis or occlusion in 6 cases. The right coronary artery showed stenosis of the orifice in 7 cases and the main vessel was severely stenosed or occluded in 7 cases. The posterior descending artery was severely stenosed in 2 cases.

This very advanced coronary atherosclerosis defeated the operation in several ways. If the left ventricle was severely damaged by ischaemia before operation, there was sometimes too little intact inuscle remaining for the patient to benefit from vein grafting or even to allow him to survive the operation. It is well recognized that necropsies commonly show more extensive myocardial infarction than is suspected during life (Edwards, 1971). It is reasonable to expect that vein grafting will improve the function of surviving muscle fibres and reduce the chances of further ischaemic necrosis, but significant regeneration of muscle fibres is unlikely to occur. Extensive left ventricular damage is detectable in life by ventricular angiography and by measuring the end-diastolic pressure. A higher operative mortality rate is well recognized when the latter is raised (Cooley et al., 1973); a ventricular ejection fraction of less than 40 per cent may be used as a contraindication to surgery (Collins et al., 1973). A non-invasive method for demonstrating the state of perfusion of the heart is now available using ${ }^{43} \mathrm{~K}$ injected into a peripheral vein and measurement of myocardial uptake (Botti and MacIntyre, 1974). Studies of the pathology of patients dying of cardiogenic shock (without operation) have revealed infarction of more than 40 per cent of the left ventricle (Bouch and Montgomery, 1970; Bolooki et al., 1971; Mundth et al., 1971 ; Page et al., 1971). In the present 10 cases, the left ventricle was affected in all, with ischaemic fibrosis in 8 cases and recent infarction in the other 2 cases. There was a fibrous aneurysm of the ventricle (resected) in 2 cases and ischaemic scarring of the posterior wall in 7 cases, anterior wall in 3 cases, lateral wall in 3 cases, and septum in 4 cases. 
Severe disease of small coronary arteries proximal or distal to the site of graft insertion may reduce blood flow in either direction. One result may be graft thrombosis. Proximal occlusion of a coronary artery may sometimes cause infarction of that part of the ventricle which was dependent upon retrograde flow from a graft (Case 6). Worsening of atherosclerosis of coronary arteries proximal to grafts, more severe than in non-grafted vessels, has been well documented in studies with pre- and postoperative coronary angiograms (Aldridge and Trimble, 1971; Bousvaros, Chaudry, and Piracha, 1972; Malinow et al., 1973; Diethrich and Prian, 1973). Experimentally, it has been shown that blood flow is reduced by about 50 per cent in a coronary artery proximal to a graft; flow in a stenosed coronary artery proximal to a graft is decreased even more (Kakos et al., 1972). The resulting stasis encourages thrombosis which in turn contributes to the formation of more atherosclerotic thickening (Duguid, 1946; Heard, 1949). Another reason for proximal deterioration may be probing during the operation. This was thought to be the explanation for the haemorrhage into the atherosclerotic anterior descending artery proximal to the anastomosis in Cases 9 and 10. Spontaneous haemorrhage in coronary plaques has been reviewed by Friedman (1970).

A practical problem observed in the present study and not sufficiently widely appreciated; results from severe atherosclerotic narrowing of coronary ostia. The ostium of the right coronary artery was severely narrowed in 7 out of 10 of the present cases, and of the left in 3 cases. Ostial narrowing may jeopardize the blood supply to the myocardium in two practical circumstances, viz. by causing gripping of the catheter during coronary angiography, and by interfering with, or preventing, coronary artery cannulation and perfusion during an accompanying aortic valve replacement procedure. Ventricular fibrillation and myocardial infarction have been recorded after coronary arteriography (Sones and Shirey, 1962; Gau et al., 1970; and the present Case 1). It has been suggested that the Judkins type of catheter (Judkins, 1967) may be associated with this problem more than other types, perhaps because of its extra efficiency in seeking out and entering the narrowed coronary ostia. The difficulty of perfusing narrow coronary ostia at operation has been discussed by Effler and co-workers (1967).

A higher mortality has been reported when it has been necessary to operate on heart valves or ventricular aneurysms at the same time as inserting vein grafts (Heimbecker et al., 1967; Kay et al., 1970, 1972; Danielson, Gau, and Davis, 1973; Cooley et al., 1973). Three of the present cases were in this category (Cases 2, 3, and 5). The main reason for the higher mortality in such patients may be the poor condition of the left ventricle before operation.

Death was caused by pulmonary embolism in 2 cases. This occurred during the operation in Case 8, and $2 \frac{1}{2}$ weeks later in Case 10. Pulmonary infarcts were also found at necropsy in Cases 6 and 9. While pulmonary embolism might be expected to occur very commonly in bypass graft patients, as a result of the presence of predisposing factors such as heart disease, postoperative hypercoagulability, and operation on leg veins, further experience suggests that there may not be an especially high incidence of fatal embolism in these patients (S. Lennox, 1974, personal communication).

Cerebral damage (Cases 4 and 7) is a wellrecognized complication of heart surgery though far less common now than formerly. Some kind of cerebral disturbance at 3 days after open heart surgery was reported by Branthwaite (1972) in $19 \cdot 2$ per cent of her patients, especially in the older age-group, but was usually transient. The mortality was 2 per cent. In 1973, the incidence of cerebral disturbance was lower, at 7.4 per cent (Branthwaite, 1975). Prophylactic measures to eliminate microemboli and minimize the risks of hypotension and hypothermic circulatory arrest were thought collectively beneficial. There are many particles in the pump return line (Solis et al., 1974).

\section{Graft patency}

Ten of the 14 vein grafts inserted in the present series, i.e. 71 per cent, were still patent at the time of death. The other 4 were occluded by fresh or organizing thrombus. The 14 vein grafts were inserted into the following vessels (number of patent grafts in brackets): anterior descending 5 (4), circumflex 1 (1), right 5 (3), and posterior descending 3 (2) (see Table). A similar patency rate has been reported by others in necropsy material (Marti, Bouchardy, and Cox, 1971; Lespérance et al., 1972; Ross et al., 1972). Some of the patients in the present series died very shortly after operation, and there was thus evidence only of shortterm patency. In a recent necropsy study, Vlodaver and Edwards (1973) found that only 3 out of 16 grafts $(18.75 \%)$, which had been in place for 2 months or longer, were still patent. However, evidence obtained from patients restudied in life gives a truer and more hopeful picture (Ross et al., 1972; Gott, 1974; Bourassa et al., 1972). It has been found that at one year, the patency rate is 65 to 75 per cent but the occlusion rate in later years appears to be only about 5 per cent per annum (British Medical fournal, 1974). Hammond and 
TABLE Summary of operations and necropsy findings

\begin{tabular}{|c|c|c|c|c|c|}
\hline $\begin{array}{l}\text { Case } \\
\text { No. }\end{array}$ & $\begin{array}{l}\text { Indication } \\
\text { for operation }\end{array}$ & Operation & Cause of death & $\begin{array}{l}\text { State of grafts at } \\
\text { necropsy }\end{array}$ & Survival time \\
\hline 1 & Angina & Vein grafts to $A D$ and $P D$ & Myocardial infarction & Patent & Nil \\
\hline 2 & Angina & $\begin{array}{l}\text { AV replacement; vein graft } \\
\text { to } \mathrm{AD}\end{array}$ & $\begin{array}{l}\text { Thrombosis of RC and of } \\
\text { graft to AD }\end{array}$ & Thrombosed & $8 \mathrm{~d}$ \\
\hline 3 & LV aneurysm & $\begin{array}{l}\text { Aneurysm LV resected; } \\
\text { vein graft to } R C\end{array}$ & Ischaemic fibrosis LV & Patent & $3 \mathrm{wk}$ \\
\hline 4 & Angina & Vein grafts to RC and C & Cerebral softening & Patent & $10 \mathrm{~d}$ \\
\hline 5 & Angina & $\begin{array}{l}\text { Aortic valvotomy; vein } \\
\text { graft to RC }\end{array}$ & $\begin{array}{l}\text { Severe coronary artery } \\
\text { atherosclerosis; recent } \\
\text { myocardial infarction; } \\
\text { calcific aortic valve disease }\end{array}$ & $\begin{array}{l}\text { Thrombosed (shortly } \\
\text { after operation) }\end{array}$ & $6 \mathrm{mth}$ \\
\hline 6 & $\begin{array}{l}\text { Aneurysmectomy } \\
\text { considered }\end{array}$ & $\begin{array}{l}\text { Vein graft to } \mathrm{AD} \text { (no } \\
\text { aneurysmectomy) }\end{array}$ & $\begin{array}{l}\text { Ischaemic destruction much } \\
\text { of } L V \text { (old and recent } \\
\text { infarcts) }\end{array}$ & Patent & $5 \mathrm{~d}$ \\
\hline 7 & Angina & Vein graft to RC & $\begin{array}{l}\text { Thrombosis of graft; severe } \\
\text { coronary artery disease }\end{array}$ & $\begin{array}{l}\text { Thrombosis (recent) } \\
\text { and intimal fibrosis }\end{array}$ & $13 \mathrm{mth}$ \\
\hline 8 & Angina & Vein grafts to $A D$ and $P D$ & $\begin{array}{l}\text { Pulmonary embolism during } \\
\text { operation }\end{array}$ & Patent & Nil \\
\hline 9 & LV aneurysm & $\begin{array}{l}\text { Aneurysm LV resected; } \\
\text { vein graft to RC }\end{array}$ & $\begin{array}{l}\text { Ischaemic destruction of } \\
\text { much of LV (old and } \\
\text { recent infarcts) }\end{array}$ & Patent & Nil \\
\hline 10 & Angina & Vein grafts to $A D$ and $P D$ & $\begin{array}{c}\text { Pulmonary embolism ( } 2 \frac{1}{2} \\
\text { weeks after operation) }\end{array}$ & $\begin{array}{l}\text { Patent to } \mathrm{AD} ; \\
\text { thrombosed to } \mathrm{PD}\end{array}$ & $2 \frac{1}{2} w k$ \\
\hline
\end{tabular}

Abbreviations: $\mathrm{AD}=$ anterior descending artery, $\mathrm{AV}=$ aortic valve, $\mathrm{C}=$ circumflex artery, $\mathrm{LV}=$ left ventricle, $\mathrm{PD}=$ posterior descending artery, $\mathrm{RC}=$ right coronary artery.

Poirier (1973) and Flemma et al. (1972) reported patency rates of over 80 per cent. Reul and coworkers (1972) demonstrated angiographically patency of a vein graft that had been functioning for 7 years.

Early occlusion of vein grafts is usually a result of thrombus forming in the lumen when the flow is slow. Graft blood flow readings obtained at operation ideally should be in the region of 80 to $100 \mathrm{ml} / \mathrm{min}$ (Favaloro et al., 1970). It has been shown clearly that there is a fall in patency rate with flows of less than $40 \mathrm{ml} / \mathrm{min}$ (Walker et al., 1971). Occlusion has been found in more than 75 per cent of grafts with flow rates below $25 \mathrm{ml} / \mathrm{min}$ (Grondin et al., 1971a, b, c, d, e). Stagnation and occlusion are usually thought to be caused by coronary artery disease above and/or below the level of the graft insertion, but a tight anastomosis at either end of the graft may also be responsible (Bouch et al., 1972). The resulting occlusion may be of two sorts, a laminated thrombus formed initially in a moving blood stream and/or a blood clot formed in a still column of blood after the lumen has become occluded by thrombus. Early occlusion may also result from changes in the endothelium encouraging thrombosis. Experimental studies have shown mural thrombi in vein grafts during the first week, clearing later when the endothelium is restored (Brody, Angell, and Kosek, 1972a). The endothelial changes may be linked with partial necrosis of the media, and some of the intimal thickening may be of proliferating muscle cells as identified by electron microscopy (Kern, Dermer, and Lindesmith, 1972). Medial fibrosis has also been observed.

Occlusion of a vein graft some months after operation usually seems to be the result of thickening of the intima. Thrombus may eventually occur in an occluded, thickened vein, as in Case 7. It is possible that worsening of atherosclerosis in coronary arteries distal to a graft slows blood flow in the graft, and causes mural thrombosis; subsequent organization of thrombi would contribute to intimal fibrosis, as has been demonstrated in atherosclerosis (Duguid, 1946; Heard, 1949). Fibrous intimal changes have been described in vein grafts in leg arteries (DeWeese et al., 1966; DeWeese and Robb, 1971). In coronary grafts, fibroblasts proliferate in a basophilic mucoid matrix containing acid mucopolysaccharides (Vlodaver and Edwards, 1971). Intimal thickening has been observed as early as 10 days after operation (Marti et al., 1971) and is very common, occurring in one series in 6 out of 8 grafts examined $3 \frac{1}{2}$ to 9 months after operation (Aldridge and Trimble, 1971). About 5 per cent of veins may show intimal thickening at the time of insertion (Flemma et al., 1972). In comparing the intimal thicknesses of veins pathologically it is important to ensure that they have been fixed in comparable conditions of distension, because the intima appears thicker in a 
relaxed than in a distended vein. Since the grafted veins in the present study were injected under a standard pressure with the gelatin-containing mass, and fixed distended, comparisons were justifiable.

Intimal thickening may be a problem in long-term survivors and has been studied pathologically by Johnson et al. (1970a, b), Grondin et al. (1971a, b, c, d, e), Marti et al. (1971), and Vlodaver and Edwards (1971, 1973). The cause of the intimal thickening is not known at present but there are several possibilities. One suggestion is that trauma and irrigating solutions play a part (Flemma et al., 1972). Another is that the natural adventitial vessels are cut when the vein is transplanted so that the vein wall becomes ischaemic (Brody et al., 1972a; Brody, Kosek, and Angell, 1972b). A third factor suggested is the greater intraluminal pressure in a vein transplanted into an arterial circuit; haemodynamic stress is probably of great importance (Bourassa et al., 1972; Kern et al., 1972; Vlodaver and Edwards, 1973). The intima of a vein exposed to arterial pressures may react by proliferating. Fourthly, a less likely explanation is that the vein becomes atherosclerotic. Some authors have found lipid present after 18 months (Effler et al., 1971), but most evidence does not support this explanation. Atherosclerotic changes are uncommon in vein grafts in leg arteries (Downs, 1971).

More time and experience will be necessary before the importance of intimal thickening as a potential limiting factor in the usefulness of coronary vein grafts can be firmly established. Vlodaver and Edwards (1973) studied 86 coronary vein grafts in 53 necropsies and found obstruction in 30 grafts. Grafts occluding during the first month were thrombosed, but in those occluding later (up to $3 \frac{1}{2}$ years) fibrous intimal proliferation was more important than thrombosis as a cause of occlusion. In the present study, conspicuous intimal fibrosis was seen in Case 7 where the graft had been patent for about 13 months before finally becoming occluded by thrombus. Three other grafts thrombosed shortly after operation, before intimal fibrosis could take place. Flemma and co-workers (1972) illustrated a section of a thickened vein patent at 3 years. The incidence of occlusion of grafts is, however, not fairly portrayed in necropsy series. Vein grafts in atherosclerotic limb arteries are often found to be still patent when death occurs from some other cause.

Dilatation is not a problem with these grafts but localized stenosis certainly is. Bourassa and coworkers (1972) found localized stenoses, sometimes severe, in 27 out of 124 vein grafts on repeat coronary cineangiography. Seventy per cent were in the proximal third and 30 per cent in the distal third. Hammond and Poirier (1973) found stenoses in 9 per cent of their cases. Stenosis may develop at the sites of anastomosis at each end of the graft; this was a complication reported when the aorta was merely slit transversely before making the anastomosis; a transverse cut tends to close whereas a vertical cut tends to open. Best results follow removal of a small piece of aorta. Stenoses may develop along the course of the graft when venous valves open as a result of turbulence (Diethrich and Prian, 1973) with resulting formation at these sites of thrombus which organizes to become a fibrous obstruction. Valve cusp fibrosis is a recognized obstructive lesion in vein grafts in leg arteries and may require local excision (Downs, 1971).

\section{Comments on pathological technique}

In general, the method of injecting a warmed gelatinous mass directly into the warmed heart using tied-in coronary cannulae was satisfactory for the present purpose. The quality of fixation suffered to some extent from the effects of freezing and thawing for storage (Heard, 1955a, b), exposure to hot water in the unfixed state, and post-mortem autolysis. The use of a medium which could be used at room temperature would probably be better for the preservation of histological detail (Schlesinger, 1957). However, the present technique was so successful in filling the vessels required that once started it was not changed. The sizes of vessels filled were ideal for this particular study, and the results were comparable with those obtained by previous workers (Gross, 1921; Schlesinger, 1938, 1957; Harrison and Wood, 1949; Schwartz and Mitchell, 1962; Fulton, 1965). To study finer vessels, a different injection mass and different radiological equipment and films are necessary (Farrer-Brown and Rowles, 1969). For the present study, injecting smaller vessels would have produced a fine haze which would have obscured the large and medium sized vessels.

At the beginning of this project, a trial was made of a specially-constructed catheter consisting of a balloon which was inflated below the aortic valve, and a rubber bung tied into the ascending aorta (Rissanen, 1970). The mass was injected into the intervening ascending aorta and thus into the coronary arteries. Aortic root injection for coronary arteries (Baroldi and Scomazzoni, 1967) has been recommended by the World Health Organization (1970). Present experience by the author does not support that recommendation. When the mass solidifies and is fixed by formalin in the aorta, it interferes with radiological views of the coronary 
arteries in whole hearts despite careful orientation, and also with subsequent dissection and radiography of the 'unrolled' specimen. The aortic valve region is distorted by the presence and upward pull of the balloon, and, also, medium commonly leaks past the balloon down into the left ventricle, wasting medium and spoiling radiographs. The only possible disadvantage of cannulating the coronaries directly as in the present study, was that the ostia were not visualized radiologically, but this was no problem because they could be examined perfectly well by the naked eye at the time of cannulation.

\section{Concluding remarks}

Johnson and his colleagues (1969) thought that no patient should be refused treatment because of the extent of the coronary disease. The present study emphasizes that the pathological changes in the ischaemic left ventricle are sometimes too severe for vein grafting to improve left ventricular function (Bolooki and Jude, 1972; Diethrich and Prian, 1973; Balcon et al., 1974; Danielson et al., 1973; Spencer et al., 1971). The present study also shows that, if left ventricular function is reasonably satisfactory despite extensive severe coronary artery disease, more radical coronary surgery is neededendarterectomy and multiple vein grafts- to achieve good results. In this early series, 6 of the 10 patients who died received only one graft.

The author thanks Dr. K. F. W. Hinson for encouragement and advice, Dr. H. de C. Baker for necropsy data on Case 7, and Dr. G. Farrer-Brown for early advice on the radiography of specimens. He is grateful to physicians and surgeons at the London Chest and Brompton Hospitals for their co-operation in this study and for supplying the clinical data and helping with the interpretation of the pathological findings. The project was supported by a grant from the Clinical Research Committee of the National Heart and Chest Hospitals.

\section{References}

Alderman, E. L., Matlof, H. J., Wexler, L., Shumway, N. E., and Harrison, D. C. (1973). Results of direct coronaryartery surgery for the treatment of angina pectoris. New England Fournal of Medicine, 288, 535.

Aldridge, H. E., and Trimble, A. S. (1971). Progression of proximal coronary artery lesions to total occlusion after aortocoronary saphenous vein bypass grafting. Fournal of Thoracic and Cardiovascular Surgery, 62, 7.

Anderson, R. P., Hodam, R., Wood, J., and Starr, A. (1972). Direct revascularization of the heart. Early clinical experience with 200 patients. Fournal of Thoracic and Cardiovascular Surgery, 63, 353.

Balcon, R., Honey, M., Rickards, A. F., Sturridge, M. F., Walsh, W., Wilkinson, R. K., and Wright, J. E. C. (1974). Evaluation by exercise testing and atrial pacing of results of aortocoronary bypass surgery. British Heart fournal, 36, 841.

Baroldi, G., and Scomazzoni, G. (1967). Coronary Circulation in the Normal and Pathologic Heart. Armed Forces Institute of Pathology, Washington.
Bolooki, H., and Jude, J. R. (1972). Objective assessment of results with coronary bypass grafts. Annals of Thoracic Surgery, 14, 107.

Bolooki, H., Lemburg, L., Ghahramani, A., Economides, C., Caldwell, T., and Jude, J. R. (1971). Clinical, surgical, and pathologic correlation in patients with acute myocardial infarction and pump failure. Circulation, 44, 1034.

Botti, R. E., and MacIntyre, W. J. (1974). Surgical revascularization of the myocardium demonstrated by injection of ${ }^{43} \mathrm{~K}$ into a peripheral vein. Fournal of Thoracic and Cardiovascular Surgery, 67, 682.

Bouch, D. C., Julian, D. J., Kitchen, A. H., Oliver, M. F., and Wade, J. D. (1972). Surgery for coronary artery disease. British fournal of Surgery, 59, 801.

Bouch, D. C., and Montgcmery, G. L. (1970). Cardiac lesions in fatal cases of recent myocardial ischaemia from a coronary ca.e unit. British Heart fournal, 32, 795.

Bourassa, M. G., Lespérance, J., Campeau, L., and Simard, P. (1972). Factors influencing patency of aortocoronary vein grafts. Circulation, 45, Suppl. I, 79.

Bousvaros, G., Chaudry, M. A., and Piracha, A. R. (1972) Progression of proximal coronary arterial lesions to total occlusion after vein graft surgery and its effects. American fournal of Cardiology, 29, 255.

Branthwaite, M. A. (1972). Neurological damage related to open-heart surgery. A clinical survey. Thorax, 27, 748.

Branthwaite, M. A. (1975). Prevention of neurological damage during open-heart surgery. Thorax, 30, 258.

British Medical fournal (1974). Coronary artery surgery for angina, 4, 61 .

Brody, W. R., Angell, W. W., and Kosek, J. C. (1972a). Histologic fate of the venous coronary artery bypass in dogs. American fournal of Pathology, 66, 111.

Brody, W. R., Kosek, J. C., and Angell, W. W. (1972b). Changes in vein grafts following aorto-coronary bypass induced by pressure and ischemia. Fournal of Thoracic and Cardiovascular Surgery, 64, 847.

Collins, J. J., Cohn, L. H., Sonnenblick, E. H., Herman, M. V., Cohn, P. F., and Gorlin, R. (1973). Determinants of survival after coronary artery bypass surgery. Circulation, 48, Suppl. 3, 132.

Cooley, D. A., Dawson, J. T., Hallman, G. L., Sandiford, F. M., Wukasch, D. C., Garcia, E., and Hall, R. J. (1973). Aortocoronary saphenous vein bypass. Results in 1,492 patients, with particular reference to patients with complicating features. Annals of Thoracic Surgery, 16, 380.

Danielson, G. K., Gau, G. T., and Davis, G. D. (1973). Early results of vein bypass grafts for coronary artery disease. Mayo Clinic Proceedings, 48, 487.

DeWeese, J. A., and Rob, C. G. (1971). Autogenous venous bypass grafts five years later. Annals of Surgery, 174, 346.

DeWeese, J. A., Terry, R., Barner, H. B., and Rob, C. G. (1966). Autogenous venous femoropopliteal bypass grafts. Surgery, 59, 28.

Diethrich, E. B., and Prian, G. W. (1973). A proposed classification for analysis of the results of aortocoronary bypass grafts. Advances in Cardiology, 9, 100.

Downs, A. R. (1971). Repair of late vein graft occlusions. Archives of Surgery, 103, 639.

Duguid, J. B. (1946). Thrombosis as a factor in the pathogenesis of coronary atherosclerosis. Fournal of Pathology and Bacteriology, 58, 207.

Edwards, J. E. (1971). The value and limitations of necropsy studies in coronary arterial disease. Progress in Cardiovascular Diseases, 13, 309.

Effler, D. B., Favaloro, R. G., Groves, L. K., and Loop, F. D. (1971). The simple approach to direct coronary artery surgery. Fournal of Thoracic and Cardiovascular Surgery, 62, 503 . 
Effler, D. B., Groves, L. K., Suarez, E. L., and Favaloro, R. G. (1967). Direct coronary artery surgery with endarterectomy and patchgraft reconstruction. Fournal of Thoracic and Cardiovascular Surgery, 53, 93.

Farrer-Brown, G., and Rowles, P. M. (1969). Vascular supply of interventricular septum of human heart. British Heart fournal, 31, 727.

Favaloro, R. (1972). Direct and indirect coronary surgery. Circulation, 46, 1197.

Favaloro, R. G. (1968). Saphenous vein autograft replacement of severe segmental coronary artery occlusion: operative techniques. Annals of Thoracic Surgery, 5, 334.

Favaloro, R. G. (1970). Surgical Treatment of Coronary Arteriosclerosis. Williams and Wilkins, Baltimore.

Favaloro, R. G., Effler, D. B., Groves, L. K., Sheldon, W. C., and Sones, F. M. (1970). Direct myocardial revascularization by saphenous vein graft. Annals of Thoracic Surgery, 10 (2), 97.

Flemma, R. J., Johnson, W. D., Lepley, D., Tector, A. J. Walker, J., Gale, H., Beddingfield, G., and Manley, J. C. (1972). Late results of saphenous vein bypass grafting for myocardial revascularization. Annals of Thoracic Surgery, $14,232$.

Friedman, M. (1970). Pathogenesis of coronary thrombosis, intramural and intraluminal haemorrhage. In Thrombosis and Coronary Heart Disease, p. 20. Ed. by P. I. Halonen and $\mathrm{A}$. Louhija. Karger, Basel.

Fulton, W. F. M. (1965). The Coronary Arteries. Thomas, Springfield, Illinois.

Gau, G. T., Oakley, C. M., Rahimtoola, S. H., Raphael, M. J., and Steiner, R. E. (1970). Selective coronary arteriography. A review of 18 months' experience. Clinical Radiology, 21, 275.

Gott, V. L. (1974). Outlook for patients after coronary artery revascularization. American fournal of Cardiology, 33, 431.

Green, G. E. (1972). Internal mammary artery-to-coronary artery anastomosis. Annals of Thoracic Surgery, 14, 260.

Grondin, C. M., Castonguay, Y. R., Lepage, G., Meere, C., and Grondin, P. (1971a). Aortocoronary bypass grafts: early postoperative angiographic evaluation and reexploration for stenosis or thrombosis of the vein graft. Archives of Surgery, 103, 535.

Grondin, C. M., Castonguay, Y. R., Lespérance, J., Bourassa, M. G., Campeau, L., and Grondin, P. (1971b). Attrition rate of aorta-to-coronary saphenous vein grafts after one year. Annals of Thorasic Surgery, 34, 223.

Grondin, C. M., Lepage, G., Castonguay, Y. R., Meere, C., and Grondin, P. (1971c). Aortocoronary bypass graft: initial blood flow through the graft, and early postoperative patency. Circulation, 44, 815.

Grondin, C. M., Meere, C., Castonguay, Y. R., Lepage, G., and Grondin, P. (1971d). Progressive and late obstruction of an aorto-coronary venous bypass graft. Circulation, 43, 698.

Grondin, C. M., Meere, C., Castonguay, Y. R., Lepage, G., and Grondin, P. (1971e). Blood flow through aorto-tocoronary artery bypass grafts and early postoperative patency. Annals of Thoracic Surgery, 12, 574.

Gross, L. (1921). The Blood Supply to the Heart in its Anatomical and Clinical Aspects. P. B. Hoeber, New York.

Hammond, G. L., and Poirier, R. A. (1973). Early and late results of direct coronary reconstructive surgery for angina. Fournal of Thoracic and Cardiovascular Surgery, 65, 127.

Harrison, C. V., and Wood, P. (1949). Hypertensive and ischaemic heart disease: a comparative clinical and pathological study. British Heart fournal, 11, 205.

Heard, B. E. (1949). Mural thrombosis in the renal artery and its relation to atherosclerosis. Fournal of Pathology and Bacteriology, 61, 635 .

Heard, B. E. (1955a). The histological appearances of some normal tissues at low temperatures. British fournal of Surgery, 42, 430.

Heard, B. E. (1955b). Nuclear crystals in slowly-frozen tissues at very low temperatures. Comparison of normal and ascites tumour cells. British fournal of Surgery, 42, 659.

Heimbecker, R. O., Chen, C., Hamilton, N., and Murray, D. W. G. (1967). Surgery for massive myocardial infarction. An experimental study of emergency infarctectomy. Surgery, 61, 51.

Johnson, W. D., Auer, J. E., and Tector, A. J. (1970a). Late changes in coronary vein grafts. American fournal of Cardiology, 26, 640.

Johnson, W. D., Flemma, R. J., Harding, H. W., Cooper, G. N., and Lepley, D. (1970b). Surgical principles in the direct reconstruction of left coronary flow. Annals of Thoracic Surgery, 10, 141.

Johnson, W. D., Flemma, R. J., Lepley, D., and Ellison, E. H. (1969). Extended treatment of severe coronary artery disease; a total surgical approach. Annals of Surgery, $170,460$.

Judkins, M. P. (1967). Selective coronary arteriography. Part I. A percutaneous transfemoral technic. Radiology, $89,815$.

Kakos, G. S., Oldham, H. N., Dixon, S. H., Davis, R. W., Hogen, P-O., and Sabiston, D. C. (1972). Coronary artery hemodynamics after aorto-coronary artery vein bypass. An experimental evaluation. Fournal of Thoracic and Cardiovascular Surgery, 63, 849.

Kay, J. H., Dunne, E., Krohn, B. G., Tsuji, H. K., Redington, J. V., Mendez, A., Dykstra, P., and Magidson, O. (1970). Left ventricular excision, exclusion, or plication for akinetic areas of the heart. Fournal of Thoracic and Cardiovascular Surgery, 59, 139.

Kay, J. H., Redington, J. V., Mendez, A. M., Zubiate, P., and Dunne, E. F. (1972). Coronary artery surgery for the patient with impaired left ventricular function. Circulation, 46, Suppl. 2, 49.

Kern, W. H., Dermer, G. B., and Lindesmith, G. G. (1972). The intimal proliferation in aortic-coronary saphenous vein grafts. Light and electron microscopic studies. American Heart Fournal, 84, 771.

Lespérance, J., Bourassa, M. G., Saltiel, J., and Grondin, C. M. (1972). Late changes in aorto-coronary vein grafts: angiographic features. American fournal of Roentgenology, 116, 74.

Lie, J. T., Holley, K. E., Kampa, W. R., and Titus, J. L. (1971). New histochemical method for morphologic diagnosis of early stages of myocardial ischemia. Mayo Clinic Proceedings, 46, 319.

Malinow, M. R., Kremkau, E. L., Kloster, F. E., Bonchek, L. I., and Rösch, J. (1973). Occlusion of coronary arteries after vein bypass. Circulation, 47, 1211.

Marti, M-C., Bouchardy, B., and Cox, J. N. (1971). Aortocoronary by-pass with autogenous saphenous vein grafts: histopathological aspects. Virchows Archiv für pathologische Anatomie und Physiologie und für klinische Medizin, A., 352, 255.

Mundth, E. D., Buckley, M. J., Leinbach, R. C., DeSanctis, R. W., Sanders, C. A., Kantrowitz, A., and Austen, W. G. (1971). Myocardial revascularization for the treatment of cardiogenic shock complicating acute myocardial infarction. Surgery, 70, 78.

Nayar, A., and Olsen, E. G. J. (1974). The use of the basic fuchsin stain in the recognition of early myocardial ischaemia. Cardiovascular Research, 8, 391.

Page, D. L., Caulfield, J. B., Kastor, J. A., DeSanctis, R. W., and Sanders, C. A. (1971). Myocardial changes associated with cardiogenic shock. New England fournal of Medicine, 285, 133. 
Reul, G. J., Morris, G. C., Howell, J. F., Crawford, E. S., and Stelter, W. J. (1972). Current concepts in coronary artery surgery. Annals of Thoracic Surgery, 14, 243.

Rissanen, V. T. (1970). Double contrast technique for postmortem coronary angiography. Laboratory Investigation, 23, 517.

Ross, D., Sutton, R., Dow, J., Gonzales-Lavin, L., Hendrix, G., Jefferson, K., McDonald, L., Petch, M., Smithen, C., and Sowton, E. (1972). Venous graft surgery in treatment of coronary heart disease. British Medical fournal, 2, 644.

Schlesinger, M. J. (1938). An injection plus dissection study of coronary artery occlusions and anastomoses. American Heart fournal, 15, 528.

Schlesinger, M. J. (1957). New radiopaque mass for vascular injection. Laboratory Investigation, 6, 1.

Schwartz, C. J., and Mitchell, J. R. A. (1962). The relation between myocardial lesions and coronary artery disease: 1. an unselected necropsy study. British Heart fournal, $24,761$.

Solis, R. T., Noon, G. P., Beall, A. C., and DeBakey, M. E. (1974). Particulate microembolism during cardiac operation. Annals of Thoracic Surgery, 17, 332.

Sones, F. M., and Shirey, E. K. (1962). Cine coronary arteriography. Modern Concepts of Cardiovascular Disease, 31, 735.
Spencer, F. C., Green, G. E., Tice, D. A., Wallsh, E., Mills, N. L., and Glassman, E. (1971). Coronary artery bypass grafts for congestive heart failure. A report of experiences with 40 patients. Fournal of Thoracic and Cardiovascular Surgery, 62, 529.

Vlodaver, Z., and Edwards, J. E. (1971). Pathologic changes in aortic-coronary arterial saphenous vein grafts. Circulation, 44, 719.

Vlodaver, Z., and Edwards, J. E. (1973). Pathological analysis in fatal cases following saphenous vein coronary arterial bypass. Chest, 64, 555.

Walker, J. A., Friedberg, H. D., Flemma, R. J., and Johnson, W. D. (1971). Determinants of angiographic patency of aortocoronary vein bypass grafts. Circulation, 44, Suppl. 2, 108.

World Health Organization, Scientific Group (1970). The pathological diagnosis of acute ischaemic heart disease. World Health Organization. Technical Report Series, No. 441 , p. 18.

Requests for reprints to Dr. Brian E. Heard, Brompton Hospital, Fulham Road, London SW3 $6 \mathrm{HP}$. 